\title{
ENTENDIMIENTO Y NATURALEZA DE LA CIENTIFICIDAD GEOTECNOLÓGICA: UNA APROXIMACIÓN DESDE EL PRAGMATISMO EPISTEMOLÓGICO ${ }^{1}$
}

\author{
Antonio Moreno Jiménez ${ }^{2}$ \\ Departamento de Geografía \\ Universidad Autónoma de Madrid, España
}

\section{RESUMEN}

Las tecnologías de la información geográfica (TIG) están provocando un impacto de hondo calado en Geografía y otras disciplinas. En línea con las tesis de algunos filósofos de la ciencia y geógrafos, en este artículo se propone y argumenta que los cambios observados en la investigación geográfica suponen la emersión de una praxis científica nueva y distinta. A partir de la concepción de las "tradiciones de investigación" elaborada por epistemólogos pragmatistas y de las recientes contribuciones de los filósofos de la tecnología, se enuncian los elementos y rasgos fundamentales de esa emergente cientificidad geográfica sustentada en las TIG. Con ello se trata de desvelar que éstas poseen un papel mucho más esencial y profundo en la investigación que el de simples herramientas.

Palabras clave: geotecnologías, epistemología geográfica, paradigmas, tradiciones de investigación

\section{ABSTRACT \\ Understanding and nature of geo-technological science: an epistemological pragmatism based approach}

Geographical information technologies (GIT) are producing a deep impact in Geography and other disciplines. According to the thesis of some philosophers of science and geographers, in this paper it is proposed and argued that the observed changes in the research encompass the emersion of a new and distinct scientific praxis. Based on the "research traditions" concept made in the pragmatist epistemology and on the recent contributions of philosophers of technology, the main elements and characteristics of this GIT based emerging science nature are exposed. In this way, it is intended to uncover that GIT have a much more essential and deeper role on research than a simple tool.

Keywords: geotecnologies, geographical epistemology, paradigms, research traditions

\section{INTRODUCCIÓN}

El advenimiento de las geotecnologías y su elevado impacto en la Geografía, en otras disciplinas científicas y en toda nuestra sociedad no han pasado inadvertidos ya a nadie, sea investigador, docente, profesional, gobernante, empresario o simple ciudadano. Ello ha permitido hablar de una sociedad de la geoinformación, como un nuevo paso adelante del progreso humano (Compte et al., 2009; Moreno, 2010).

\footnotetext{
1 Este artículo se ha elaborado dentro del proyecto de investigación "Contaminación atmosférica urbana y justicia ambiental: metodología de evaluación y estudio de casos con sistemas de información geográfica”, financiado por el Ministerio de Ciencia e Innovación de España, referencia CSO2011-26177.

El autor desea agradecer las observaciones críticas del Dr. Escolano Utrilla y del Dr. Mateos Rodríguez sobre una versión preliminar del artículo.

2 antonio.moreno@uam.es
} 
Por ceñirnos a la parcela de los cambios que en la investigación se han desencadenado es posible hallar pronunciamientos muy dispares por parte de reconocidos autores. Así por ejemplo, a una de las geotecnologías más conspicuas, los sistemas de información geográfica (SIG), se la ha identificado como simple herramienta, pero también como campo de desarrollo tecnológico o como base principal de disciplinas emergentes tales como la geomática, la ciencia de la información geográfica o la ciencia geospacial (Berry et al., 2008). Un cierto número de opiniones emitidas en las décadas finales de la pasada centuria admitían poco más que se trataba de un mero progreso tecnológico (vid. The Professional Geographer, 1983, 35, 2). Los pareceres, sin embargo, que recogieron Wright et al., (1997), tras un debate abierto entre expertos, traslucían ya esos posicionamientos tan diferentes, los cuales poseen implicaciones conceptuales y operativas muy dispares. Unos años después Wilbanks (2004: 9) manifestaba ya sin ambages que en Geografía “... our contributions to knowledge, learning, and society at large are being reshaped by the information and computing technology revolution ..."; Sui y Morrill (2004: 82) apostillaban que "No other technological innovation in human history has affected the practice of geography in such a profound way as the computer"; y Capel (2010), se ha posicionado de manera similar al reconocer que la "Geografía se está viendo afectada de forma muy profunda por estas nuevas tecnologías".

Esa pluralidad de interpretaciones invita y reclama de quienes están inmersos en este frente de trabajo, y particularmente en el de la producción de conocimiento, un esfuerzo por clarificar la situación hasta donde sea posible y establecer algunos consensos básicos o "common ground" que contextualicen y definan las señas de identidad de la actividad que desarrollan. Este tipo de reflexiones sobre la actividad investigadora de las comunidades científicas es conveniente por cuanto ellas permiten disponer de visiones esclarecedoras de la misma, y a la vez legitimadoras. Lo primero por cuanto, al conformar una representación ideológica más o menos completa, hacen patente los rasgos esenciales de esa praxis, lo que conduce a una generación de identidad; es decir, partiendo de pautas observables concretas en el quehacer de los investigadores, señalan los elementos claves y definitorios de su labor, haciendo cristalizar a menudo hechos nuevos o diferenciales. Lo segundo, por cuanto, tales reflexiones ejercen, implícita o explícitamente, un papel de legitimadoras de esa praxis, al confrontar sus rasgos con los hallados en otras disciplinas, por ejemplo.

En la ciencia geográfica existe una larga tradición de debates sobre su ser y su devenir, que han ocasionado una conciencia bastante elevada de las bases y condiciones de la producción del conocimiento calificado de científico. En ese sentido, si bien se reconoce unánimemente que las tecnologías de la información geográfica (TIG) o geotecnologías, son la causa de los cambios de mayor calado que en nuestra disciplina sobre todo - y en algunas otras afines - se están produciendo recientemente, lo que todavía no resulta unánime es la valoración que se hace del alcance y significado de dichos cambios.

Dentro de este contexto, el principal objetivo de esta contribución será aportar alguna luz adicional al trascendental debate que algunos autores están manteniendo sobre el papel de las geotecnologías en la ciencia geográfica. Concretamente se persigue ofrecer argumentos concernientes a la cristalización paulatina de un entendimiento nuevo de la cientificidad geográfica en cuyo núcleo medular se sitúan las geotecnologías. Más aún, la proposición a defender aquí es que son precisamente ellas las que constituyen el elemento esencial de una nueva praxis científica y de un cambio en la Geografía que tiene rango epistemológico. No se discutirá, la cuestión del nacimiento o cristalización de nuevos campos disciplinares, sino en qué medida en el panorama de la ciencia geográfica se está configurando una forma distinta de investigación y el alcance o significado de dicho cambio.

En aras de una presentación ordenada de los fundamentos argumentales en los apartados siguientes se realizará primero un breve recordatorio del problematismo de la Geografía como disciplina y de algunos asuntos centrales sobre la ciencia: su naturaleza, metas y los cambios científicos. Ello se articulará en torno al eje de la racionalidad de tales cambios, de cuya discusión emanarán algunas conclusiones aceptables acerca de los diferentes planteamientos que históricamente se han observado y practicado en disciplinas como la Geografía. Tras ello, se presentará una exposición algo más amplia de una conceptualización de la ciencia desde el pragmatismo, como marco en el que la emergente cientificidad geotecnológica halla adecuado encaje y sostén. A concretar los elementos sustantivos y estructurales de esa nueva forma de creación de conocimiento científico se destinarán los siguientes apartados, tratando sucesivamente el 
alcance gnoseológico de la tecnología, la formalización y resolución de problemas de conocimiento bajo este marco, el papel singular de ciertas funciones como el pensamiento espacial visual, los rasgos más característicos de la cientificidad geotecnológica, para terminar con algunas consideraciones acerca de su capacidad de resolución de problemas y un breve balance y conclusión.

\section{EL PROBLEMATISMO DE LA CIENTIFICIDAD EN LA GEOGRAFÍA}

Sea cual sea el criterio que se adopte para establecer el alumbramiento de la Geografía contemporánea3 lo que resulta patente es que se ha mostrado como una disciplina ontológicamente problemática. Los diversos condicionantes de carácter económico, político, filosófico-ideológico o corporativo que, como en cualquier otra disciplina, subyacen a sus cambios y re-definiciones han sido bastante evidenciados ${ }^{4}$. Pese a que tales transformaciones pueden entenderse orientadas a mantener su "racionalidad" como ciencia y su significación para la comunidad, el cuestionamiento de su esencia aparece como una constante en el tiempo. La preocupación por establecer el dominio de su quehacer científico, sus señas de identidad diferenciales de otras disciplinas y su status científico parecen una especie de "dolencia" crónica. La consulta a la bibliografía citada depara toda clase de posicionamientos al respecto sobre las cuestiones anteriores, en ocasiones notoriamente a la defensiva. Las respuestas se han buscado por muy diversas vías y con las fórmulas más dispares. En conjunto parecen haber sido tres las principales fórmulas ensayadas por los geógrafos para tal fin, centradas respectivamente en definirla por su objeto, su enfoque o su método, aunque se pueden hallar otras propuestas y variantes en la bibliografía (vid. Moreno, 1989: 54-61).

Asumiendo que en la disciplina existen un conjunto de elementos estructurantes (problemas o cuestiones centrales, conceptos generales clave, etc.) que constituyen un suelo común, cabría preguntarse: ¿Existe un entendimiento de ellos también común entre los geógrafos?, ¿se abordan bajo el mismo prisma?, ¿se conceptualizan de modo uniforme e invariante? El examen de la bibliografía geográfica empírica, así como los trabajos de reflexión teórica desarrollados sobre ella, conducen a una respuesta negativa. Esto, por otro lado, ni debería resultar extraño, ni preocupante, sino más bien al contrario. Como sensatamente apuntó Couclelis (1982: 105) al respecto, "La fragmentación de la investigación no es en sí misma necesariamente un mal: el mundo, después de todo, es un lugar muy variado y necesitamos todas las perspectivas que podamos conseguir".

El entendimiento de la Geografía, como el de cualquier otro campo científico, no cabe concebirlo como algo inmutable y universal, sino que se nos aparece como algo relativo. Son las reflexiones emanadas de la epistemología las que proporcionan las perspectivas más cabales para establecer la naturaleza de la cientificidad y su particularización en las diversas disciplinas. En este sentido, los debates sobre la racionalidad en la ciencia y en los cambios científicos son los que, como efecto derivado, han propiciado la delineación de los marcos de referencia epistemológicos más clarificadores para examinar la cientificidad y su entendimiento en dichas disciplinas.

Baste, como ejemplo, con recordar la ampliamente difundida teoría de Kuhn (1962), que se sustentaba en la idea de paradigma como "... toda la constelación de creencias, valores, técnicas, etc., que comparten los miembros de una comunidad dada". Su propuesta alcanzó de lleno a la Geografía y dio lugar a ensayos de interpretación del devenir de la misma dentro de la secuencia ciencia normal-crisis-revolución-nueva ciencia normal-nueva crisis, con fidelidad variable a ese esquema, por parte de diversos autores tales como Johnston (1979), Harvey y Holly (1981), Estébanez (1982), Holt-Jensen (1981) o Buzai (1999). Ello no obstante, procede recordar que también se formularon críticas a la aplicación de tal esquema (v. g. Stoddart, 1981).

Quizá sea Johnston (1983: 4 y ss.) uno de los autores que haya determinado más certeramente el alcance de las discrepancias que sobre el tema han mantenido los geógrafos. A su entender la profundidad

\footnotetext{
3 Sobre este asunto se cuenta con una importante bibliografía centrada en la evolución de la disciplina y sus antecedentes, por ejemplo James (1972), Broc (1969) o Quaini (9181), además de las diversas obras generales de historia de la Geografía, donde los autores se pronuncian sobre determinadas fechas y criterios, por ejemplo Capel (1981, 1987), Claval (1974), Gómez, Muñoz y Ortega (1982), Meynier (1969), etc.

4 Además de las obras citadas en la nota anterior resultan pertinentes sobre el tema las de Buttimer (1980), Claval (1984), Estébanez (1982), Freeman (1961), Holt-Jensen (1981) y Johnston (1979).
} 
de las diferencias involucra primero al nivel ontológico, esto es, a la entidad o existencia de lo que puede ser conocido; segundo al nivel epistemológico, es decir, a la teoría del conocimiento; y tercero, como derivación, al escalón metodológico. En definitiva, las raíces de las divergencias en la conceptualización y abordaje de los problemas centrales de la Geografía hay que buscarlas en el plano filosófico. La existencia de distintas filosofías de la disciplina, es en última instancia, la que da cuenta de esos enfoques, calificados a menudo de alternativos, que se adoptan en las investigaciones concretas. El mencionado autor (Johnston, 1983) propuso y desarrolló su análisis sobre la base de cuatro grandes grupos de enfoques filosóficos: empirista, positivista, humanista y estructuralista.

Sin entrar a discutir tal propuesta, muy sugestiva como interpretación, cabe recordar que dentro del panorama actual y pasado de la Geografía, se han realizado otras taxonomías diferentes, en parte por la multiplicidad de doctrinas filosóficas que impregnan los estudios geográficos y, en parte, porque la práctica investigadora es lo suficientemente abigarrada como para que muchos trabajos sean difícilmente clasificables, eclécticos y representen "impuramente" los rasgos de cualquier paradigma o enfoque. Los arquetipos ayudan a clarificar a costa de una simplificación, a veces seria, de la realidad. En cualquier caso, y como conclusión primordial de los debates habidos, parecen rechazables las doctrinas que postulan un criterio único, universal e intemporal para la cientificidad y la racionalidad científica. Este punto, básico para nuestra meta aquí, será tratado con más detenimiento en los apartados siguientes.

\section{BREVES CONSIDERACIONES SOBRE EL ENTENDIMIENTO DE LA CIENCIA Y DE LOS CAMBIOS CIENTÍFICOS}

La naturaleza de la ciencia es una gran cuestión que todo cultivador de ella se ha planteado alguna vez. Sin entrar a fondo en ello, cabría recordar que el vocablo, como señaló Wartofsky (1968: 31), puede apuntar a dos significados diferentes: bien un cuerpo de conocimientos y verdades acumuladas, bien al proceso de investigación en sí mismo. Para nuestros fines aquí es ésta segunda acepción la que resulta pertinente.

Entre los problemas generales de la ciencia que han sido objeto de mayor atención dos merecen mencionarse: por un lado, la posibilidad de una definición absoluta de ella y, por otro, la cuestión de sus fines últimos. Por lo que concierne al primero no son pocas las argumentaciones que han puesto en tela de juicio la posibilidad de un concepto universal y atemporal de ciencia. Podría traerse a colación al respecto la conclusión postulada por los historiadores de la ciencia, como por ejemplo Bernal (1972), quien afirmó taxativamente que la epistemología, bases y programa de una ciencia están en revisión continua.

Respecto a la segunda, los fines de la ciencia, son numerosos los textos en que se alude a la búsqueda de la verdad o del conocimiento cierto. Tal es la postura de los racionalistas. Sin embargo, ese planteamiento queda seriamente controvertido cuando se reflexiona sobre la veracidad en la historia de las ciencias. Newton-Smith (1981: 14) colegía en su trabajo que "todas las teorías físicas del pasado han tenido su apogeo y con el tiempo han sido rechazadas como falsas". De unas conclusiones tan pesimistas como esa surgieron propuestas de atribuir a la ciencia metas menos pretenciosas y más acordes con la limitación de la mente humana. Popper $(1968,1975)$, por ejemplo, defendió como alternativa la idea de aproximación a la verdad o verosimilitud, pero su intento de clarificar tal noción, si nos atenemos a la argumentación crítica presentada por Newton-Smith (1981, cap. III), resulta en un fracaso.

Ante tal estado de cosas la retirada ha sido mayor y otros epistemólogos, como por ejemplo el pragmatista Laudan (1981: 145), postuló un horizonte que parece mucho más aceptable "por el momento". Dicho autor planteó una atractiva idea: "la meta de la ciencia es asegurar teorías con una alta efectividad de resolución de problemas. Desde esta perspectiva, la ciencia progresa sólo en el caso de que las teorías sucesivas resuelvan más problemas que las precedentes".

Desde una perspectiva más general, las dos cuestiones señaladas antes pueden subsumirse en un antiguo debate atinente a la racionalidad e irracionalidad en la ciencia y en el cambio científico. Expresado de forma directa el asunto atañe a dos preguntas radicales de este tenor: ¿Puede afirmarse la existencia de racionalidad en el quehacer de los científicos?, ¿puede sostenerse la existencia de una sola y universal forma de racionalidad científica?

Esta última pregunta es la que en términos filosóficos encarna la dicotomía racionalismo-relativismo que, como esquematizó Chalmers (1984: 143-146), podría expresarse de esta forma: el racionalista 
radical defiende un criterio único, universal e intemporal para juzgar comparativamente teorías rivales; la distinción entre lo que es y no es ciencia y resulta nítida. Una teoría será científica si supera satisfactoriamente el test establecido como criterio. Por su parte el relativista rechaza tal universalidad e invariancia; el juicio sobre las teorías se sustentará sobre criterios que varían entre los individuos y comunidades; tales criterios reposan sobre valores e intereses por lo que la "ciencia" y su devenir deben ser investigados desde perspectivas sociológicas, psicológicas, políticas, etc.

Embates fuertes contra la racionalidad de la ciencia han provenido de diversos autores de los que solo citaremos dos: Kuhn (1962) y Feyerabend (1974). La concepción kuhniana resulta ambivalente sobre este punto. Por un lado postula la racionalidad de la práctica científica dentro de lo que llamó "ciencia normal": los debates y confrontaciones se dirimen sin especial problema, dado que cada paradigma ofrece estándares mediante los cuales las hipótesis, teorías y experimentos han de ser generados y juzgados. Por otro lado, asume un cierto irracionalismo en la confrontación entre paradigmas rivales, lo que le ha granjeado el calificativo de historicista (Doppelt, 1983: 107) y de relativista. Los paradigmas, en la idea mantenida por Kuhn, son inconmensurables en la medida en que dada su naturaleza ${ }^{5}$, no existe argumento lógico alguno que demuestre la superioridad de uno sobre otro. Su proclamación de que los condicionantes que gobiernan el cambio (progreso) científico, esto es, la sucesión de paradigmas, son de índole psicológica, sociológica e histórica ha tenido la virtud de recoger muchos datos empíricamente observados sobre el devenir de la ciencia; a cambio el coste ha sido elevado, la racionalidad del proceso ha debido descartarse. El abrazo a un nuevo paradigma podría asemejarse a una especie de "conversión religiosa".

De ello se ha inferido el relativismo de Kuhn que algunos califican de extremo, y por lo tanto conducente al rechazo de la racionalidad en el cambio (progreso) científico, pero que otros han definido como moderado. Tal es la opinión de, por ejemplo, Doppelt (1983: 111-114) quien, tras su análisis, halla que en la concepción de Kuhn se establece la existencia, para los científicos, de buenas razones (de un tipo que son universalmente aplicables en la vida científica), a la hora de sustituir un paradigma viejo por otro nuevo. Ellas impedirían calificar el cambio científico de irracional. Pese a todo, son los límites de la racionalidad humana quienes dejan indeterminado el proceso de elección entre paradigmas y los que, en última instancia, obligan al recurso de factores sociológicos y psicológicos para dar cuenta del proceso. La misma conclusión que Kuhn, como racionalista moderado en cuanto al cambio científico, sostiene Newton-Smith (1981: 112-124), quien encuentra en los escritos de dicho autor una lista parcial de al menos cinco características (exactitud, consistencia, amplio alcance, simplicidad y fertilidad) de las buenas teorías científicas que constituirían la base compartida entre los estudiosos para la elección entre ellas. Un relativo consenso entre científicos les otorgaría el papel de estándares supra-paradigmáticos por lo que garantizarían un cierto nivel de racionalidad en la confrontación de paradigmas. La irracionalidad se introduce, sin embargo, a la hora de aplicarlos: la interpretación de cada uno de tales rasgos y los desacuerdos en cuanto al peso relativo que se les concediese entre sí (obediente entonces a factores subjetivos).

Otro de los ataques frontales contra la racionalidad de la ciencia procede de Feyerabend (1974), particularmente por su defensa a ultranza de la inconmensurabilidad de las teorías, es decir, la imposibilidad de comparar lógicamente teorías rivales": "Sus contenidos no pueden ser comparados, ni es posible hacer un juicio de verosimilitud excepto dentro de los confines de una teoría particular... lo que quedan son juicios estéticos, juicios de gusto, y nuestros propios deseos subjetivos" y los intereses de cada uno (Feyerabend, 1974: 133).

Las posiciones descritas son buenos ejemplos de argumentaciones bien reconocidas entre epistemólogos y científicos de las que cabe colegir la prevalencia de dos ideas: por un lado que la ciencia es una actividad con una racionalidad limitada o relativa y, por otro, que no existe una única norma de racionalidad científica. Las interpretaciones históricas de la cientificidad y sus cambios que autores como Khun (1962) con sus "paradigmas", Lakatos (1993) con sus "programas de investigación" o Laudan (1981)

\footnotetext{
5 Que incluiría las normas necesarias para legitimar el quehacer dentro la ciencia (disciplina) que rige: algunos principios metafísicos muy generales, los supuestos teóricos (comparables al "núcleo central" de Lakatos, 1974) y los métodos y técnicas de investigación.

6 La justificación radica en que, al depender la observación de la teoría, los significados e interpretaciones de los conceptos y de los enunciados observacionales que los empleen dependerán del contexto teórico en que surjan (Chalmers, 1984, p. 191).
} 
con sus "tradiciones de investigación", pese a las limitaciones y aspectos discutibles de cada una, constituyen la derivación más sostenible de unas tesis que han logrado concitar un amplio consenso acerca de ciertos puntos capitales. Yendo más lejos aún, Durbin (1989: 51-52), hace notar que Kuhn articuló su propuesta a partir de una lectura de las principales revoluciones de las ciencias físicas, pero que el mismo autor ya apuntaba algo más tarde que quizá habría que reconsiderar la base de su análisis y examinar la propia estructura de las comunidades científicas y cómo en ellas se concreta el lenguaje y la resolución de problemas. Durbin, con un enfoque pragmáticamente basado, profundizó en esa dirección y aseveró, siguiendo a otros autores, que "no es solo la comunidad particular, como Kuhn la conceptuaría, la unidad de análisis; es el <<acto social>> (i.e. la praxis) de una comunidad lo que la torna inteligible. $\ldots<$ La unidad de existencia es el acto >>". A su juicio, la limitación de las diversas epistemologías de la ciencia (no dar nunca la imagen total), es que no sitúan "su idea dentro del acto social de la ciencia tal como ha sido practicada históricamente - esto es, dentro de la praxis de un grupo de científicos cuyo mundo-tomado-por-garantizado es sacudido por un descubrimiento anómalo o problemático que entonces coloca a la comunidad en el camino para establecer otro mundo...", epistemológicamente hablando. En el marco de nuestra propuesta, el advenimiento de las geotecnologías geodigitales, estaría actuando como ese revulsivo.

Asumiendo tales premisas, expondremos en el apartado siguiente las ideas básicas de la epistemología pragmatista, singularmente de Laudan y sus extensiones ulteriores. Ellas nos servirán para sustentar después una reivindicación de la praxis investigadora "geotecnológica", como algo nuevo y esencialmente distinto de otros entendimientos de la cientificidad que existen y se cultivan en la actualidad.

\section{LA CIENTIFICIDAD DESDE EL PRAGMATISMO RACIONALISTA MODERADO}

\subsection{Las propuestas de Laudan sobre la ciencia y su progresión}

Según Laudan (1981: 151), las tradiciones de investigación “... generalmente constan de al menos estos dos componentes: 1) Un conjunto de creencias acerca de las clases de entidades y procesos que conforman el dominio de indagación (al ontología), y 2) un conjunto de normas epistemológicas y metodológicas acerca de cómo investigar ese dominio, cómo comprobar las teorías, cómo recoger los datos, y cosas similares". Es clara la similitud con las propuestas de los previamente citados Kuhn y Lakatos. La racionalidad científica estaría garantizada en la actividad investigadora dentro de cada paradigma o tradición de investigación en tanto en cuanto se ajustase a las pautas aceptadas en su seno. El problema afloraría al confrontar investigaciones realizadas bajo distintos paradigmas.

Es con respecto al cambio científico donde la formulación de Laudan difiere notoriamente de la de Kuhn, al tiempo que recoge algunas de las objeciones hechas a las posturas historicistas-irracionalistas. Frente al cambio por sustitución de paradigmas, Laudan (1981: 152-153) propone, como más realista, la coexistencia de diferentes tradiciones de investigación rivales y la permanencia de los debates sobre las cuestiones conceptuales fundamentales que, según Kuhn, estaban ausentes en los períodos de ciencia normal. Este hecho no parece muy ajustado a la realidad de la historia de las ciencias. En efecto, el panorama observado en la Geografía durante las últimas décadas, con varias tradiciones postulando sus propios entendimientos y desarrollos, con sus delimitaciones del campo de interés, de clases de problemas y modos de abordarlos, y con permanentes debates que obligan a justificaciones y reajustes, resulta así más inteligible y coherente bajo el prisma propuesto por Laudan.

Pero yendo más allá, Laudan (1981: 153-154) se posiciona en un punto razonable y convincente ante el dilema ciencia-no ciencia, esto es, el clásico problema de la demarcación. A su entender no hay una diferencia de clase fundamental entre investigación científica y otras formas de indagación intelectual. Similares propósitos (dar sentido al mundo y a nuestra experiencia) y similares procedimientos de evaluación, dice, operan a lo largo del amplio espectro de disciplinas intelectuales. A lo sumo, sostiene, el desigual grado de progreso que las llamadas "ciencias" presentan respecto de las "no-ciencias" puede responder a diferencias de grado, no de clase. Incluso concede que los vigorosos procedimientos de comprobación (metodologías) que muchas ciencias poseen no pueden ser constitutivos de lo científico, puesto que ciertas ciencias no los usan. Para él "hace ya tiempo que se ha abandonado el prolongado 
prejuicio "cientifista" que sostiene que las ciencias y el conocimiento firme son co-extensivos", esto es, coincidentes. Con tan respetuosa actitud hacia las diversas formas de conocimiento humano, Laudan no sólo tiende un puente entre esa polaridad que ha acarreado tantos malentendidos entre ciencias físico-naturales y ciencias humanas, sino que también abre la vía a la conciliación y co-existencia entre las tradiciones "cientifistas" e historicistas que durante largo tiempo han pugnado y se han condenado mutuamente en las ciencias sociales, en general, y en la Geografía en particular.

Otra característica destacada de la concepción de Laudan (1981: 148-149) radica en su aceptación del cambio (progreso) científico sin retención acumulativa. La casi totalidad de los modelos racionales de cambio científico (incluidos los de Popper y Kuhn) asumen la idea de que la sustitución de teorías conlleva un rasgo ineludible: las nuevas deben contener a las precedentes en lo que concierne a capacidad explicativa o éxito. Ante la evidencia, por él aducida, de ejemplos en los que no se da tal circunstancia, reclama la necesidad de un modelo de cambio que incorpore esa posibilidad. En tal terreno él apunta solamente una dirección de búsqueda (ciertamente difícil), más que una solución desarrollada: una contabilidad de problemas resueltos frente a anomalías observadas de teorías rivales (una especie de análisis coste-beneficio) ofrecería una base para una interpretación racional del cambio. En cualquier caso, asevera, los principios específicos y "locales" que los científicos utilizan para evaluar teorías no son fijos permanentemente, sino que se han modificado a lo largo del devenir de la ciencia. Al respecto, y ante teorías enfrentadas, las actitudes de los científicos no se limitan a la polaridad aceptación-rechazo, sino que lo más parecido a la realidad es un continuo de actitudes cognitivas entre ambos extremos (Laudan, 1981: 150) y de ahí que se hable de la necesidad de elaborarlas más o de profundizar en ciertos aspectos, aunque se les conceda cierta aceptación.

La aplicación de estas ideas a la Geografía permite dar cuenta de la emersión y desarrollo de diferentes teorías sobre un mismo problema (por ejemplo el caso de las teorías sobre la estructura interna de la ciudad, la difusión del desarrollo o de las innovaciones, etc.) que son cultivadas simultáneamente, que no subsumen totalmente unas a las otras y que son apoyadas de forma desigual, por cuanto a menudo resultan parciales y eventualmente complementarias.

La clave central que Laudan propone para dar cumplida respuesta a todos esos requisitos no es sino la meta por él planteada para la ciencia: la resolución de problemas. Conviene clarificar un poco el significado de esta oferta pragmatista. Tras haber descartado por trascendente e inalcanzable, según se expuso más arriba, la búsqueda de la verdad, el autor nos aboca a un horizonte que parece irrenunciable. Más concretamente, y en esto Laudan recoge un ingrediente de indudable valía en la tradición científico-natural y de notoria presencia así mismo en las ciencias sociales, el autor postula que "el propósito de la ciencia es asegurar teorías con una elevada efectividad de resolución de problemas" (Laudan, 1981: 145). En cuanto a la noción de teorías científicas, el autor asume la articulada por los empiristas lógicos como "una red de enunciados que, junto con las condiciones iniciales, conduce a explicaciones y predicciones de fenómenos específicos" (Laudan, 1981: 150) y que son habitualmente sometidas a las pruebas empíricas por los científicos.

Ahora bien, ¿qué son los problemas y las soluciones? Respecto a los primeros Laudan (1977, cap. 1 y 2; 1981: 146-148) establece dos grandes categorías: empíricos y conceptuales. Una teoría (o creencia) debe así ponerse a prueba en dos planos: por un lado debe atender a la coherencia con la red de relaciones conceptuales de nuestras creencias; por otro, debe atender al soporte proveniente de la realidad empírica. La meta entonces radica en asegurar teorías que por un lado minimicen los problemas conceptuales, y por otro que resuelvan el máximo número de problemas empíricos suscitando, simultáneamente, el mínimo número de anomalías (problemas resueltos por teorías rivales y no por ésta).

Resulta obligado añadir que, bajo la rúbrica de problemas conceptuales, el autor incluye también el que surge al intentar evaluar teorías pasadas con los estándares actuales de racionalidad. La opinión de Laudan, que compartimos, postula que "las estrategias evaluadoras de los científicos en épocas anteriores difieren de las nuestras ...", por lo cual "los enfoques de los científicos anteriores acerca de cómo deben evaluarse las teorías han de entrar en los juicios sobre el grado de racionalidad de aquellos científicos al comprobar sus teorías en la forma como lo hacían". La relatividad histórica en la racionalidad de la ciencia es algo que queda pues integrada en su concepción. 
Por lo que respecta a las soluciones, éstas deben darse para los dos tipos de problemas enunciados. Expresado de forma simple se diría que un problema empírico está resuelto cuando, en un determinado contexto de indagación, los científicos no lo contemplan como una cuestión sin respuesta, esto es, cuando creen que entienden por qué la situación planteada por el problema es como es. Ello presupone la existencia de una teoría que resuelve con sentido ese problema (Laudan, 1977: 22). Relatado de un modo más formal: una teoría resuelve un problema empírico cuando funciona (significativamente) en cualquier esquema o inferencia cuya conclusión es un enunciado del problema (junto con las condiciones iniciales y límites apropiados) ${ }^{7}$. Una teoría resuelve o elimina un problema conceptual cuando no exhibe una dificultad conceptual de su predecesora.

En su razonamiento concerniente a los problema empíricos Laudan (1977: 23-26) aduce y ejemplifica que una solución, bajo este prisma no implica una exacta correspondencia entre resultados teóricos y experimentales, sino que normalmente sólo se requiere un parecido aproximado. De ello se infiere la posibilidad de que teorías diferentes pueda resolver (i.e. dar cuenta) el mismo problema (empírico o conceptual) por lo que queda espacio para la convivencia y reconocimiento de teorías competidoras (y tradiciones de investigación con teorías que incluyan y "resuelvan" el mismo problema). Una formulación marxista o funcionalista de la segregación social intra-urbana pueden así coexistir aceptablemente. La noción de solución es, por tanto, altamente relativa y comparativa (a diferencia del concepto lógico de explicación mucho más exigente en cuanto a veracidad de la teoría); lo que cuenta como solución a un problema en un momento no tiene que ser considerada como tal siempre. Por otro lado, y como ya se señaló antes, según este autor, para lo que constituye una solución es irrelevante si la teoría es verdadera o falsa (de forma absoluta), punto éste que se retomará críticamente más adelante.

En síntesis, la concepción de Laudan trata de sortear las dificultades de Lakatos, o las soluciones irracionales del cambio científico, moderada en Kuhn o extrema en Feyerabend, a la hora de comparar teorías y tradiciones de investigación. Prescindiendo de la idea de aproximación a la verdad, el autor propone una vía que preserva la racionalidad del progreso científico. La ciencia, dice, progresa sólo en el caso de que las teorías sucesivas resuelvan más problemas que sus predecesoras (Laudan, 1981: 145). El abandono o cambio de teorías y tradiciones de investigación se supeditan a esa efectividad resolutiva que, a su vez, es una función del número e importancia de los problemas empíricos resueltos y de las anomalías y problemas conceptuales que afronta. Al respecto, clarifica el autor, deben diferenciarse dos caras: la adecuación (o aceptabilidad) presente y su carácter más o menos prometedor. Una teoría (o tradición de investigación) más adecuada (aceptable) que otra implica que sea, hasta y en un momento dado, más efectiva resolviendo problemas. Se trata pues de un criterio que concede mucho peso al pasado. Sin embargo, añade, ello es una base insuficiente para evaluar su potencial futuro. La búsqueda de teorías con un potencial de fertilidad tal que amplíen el abanico de lo que explicamos y predecimos conduce a los científicos a explorar nuevas teorías y tradiciones de investigación tales que, aunque con menguado soporte todavía, ofrezcan una elevada tasa de progreso (efectividad resolutiva); esto es, que resulten prometedoras (Laudan, 1981: 151-152). A diferencia de otras posturas epistemológicas (e.g. las de Popper, Carnap o Lakatos) que identifican ambas dimensiones, la concepción de este autor, posibilita que, al evaluar con fines diferentes (retrospectivos o prospectivos) las ideas científicas, se investiguen y emerjan nuevos proyectos como algo consustancial y permanente en la práctica intelectual. Por otro lado, la mayor o menor aceptación de un teoría (o tradición) no es algo que deba descansar únicamente en una serie de rasgos de ella ${ }^{8}$, tales como el haber pasado un cierto número de test (como propusieron los inductivistas o el mismo Popper), sino que su valoración debe ser siempre relativa a los méritos de teorías rivales: "Sólo cuando comparamos su efectividad y progreso a los de teorías competidoras estamos en posición de ofrecer algún consejo sobre qué teorías deben ser aceptadas, seguidas y cultivadas" (Laudan, 1981: 154).

\footnotetext{
Esta definición entronca con el enfoque nomológico-deductivo de la explicación, sin embargo, la condición necesaria en él de que las premisas sean verdad o estén bien confirmadas es rechazada por Laudan. Para éste, basta con que el problema y la teoría estén en una cierta relación formal, con lo que se aleja de algunos de los problemas planteados por la confirmación. Sobre las distintas propuestas concernientes al problema de la explicación resulta de sumo interés la recopilación hecha por Pitt (1988).

8 Los intentos de determinar, epistemológica y pragmáticamente, la naturaleza y rasgos de las teorías se hallan de forma abundante. Pueden verse Bunge (1969, cap. 7 y 8, 1978, 1980), Mosterín (1984), Moulines (1982), Newton-Smith (1981, p. 226-232), Thuillier (1975), y en la literatura geográfica, Harvey (1969), Amedeo y Golledge (1975, cap. 2) o Beguin (1985).
} 


\subsection{Las críticas y extensiones a la concepción de Laudan}

El discurso de este autor, en cuyo comentario nos hemos extendido adrede por su virtud clarificadora, presenta algunos flancos abiertos a la crítica que ya han sido puestos de relieve y cuya consideración resulta oportuna aquí.

A) En primer lugar, el problema métrico; como dice Newton-Smith (1981: 192), "estamos a un milenio de poseer una técnica para medir la importancia de un problema o una anomalía" por lo que, según él, esa vía parece poco prometedora.

La discusión que de ello realiza Doppelt (1983: 129-132) le lleva a corroborar que Laudan no ha especificado un principio general de comparación. Si cada tradición de investigación posee sus propios criterios para determinar la efectividad resolutiva de problemas y éstos no necesitan ser compartidos por las otras, se cae en el relativismo. Doppelt (1983: 133 y ss.), en consecuencia, plantea la necesidad de una modificación de la teoría del progreso científico de Laudan y ofrece algunos ítems sugerentes y prometedores tratando, precisamente, de concretar y desarrollar lo que Laudan no hizo. La base para ello estriba en mostrar cómo, a partir de la idea de acumulación parcial entre teorías y tradiciones de investigación de una disciplina, pueden hallarse elementos para sustentar esa evaluación. Laudan en su afán por desmarcarse de la idea de acumulación rigurosa del conocimiento científico, impuesta por el positivismo y no consistente con la historia de la ciencia, había propuesto el progreso sin acumulación, pese a que creía que existe una cierta acumulación al nivel de problemas empíricos.

La argumentación, en síntesis, de Doppelt es como sigue. La unidad de una disciplina y su progreso únicamente es inteligible a partir de la asunción de que todas las tradiciones de investigación de ella comparten un tronco más o menos común de problemas empíricos, conceptos y asunciones. Lo que cuenta como un problema empírico para una tradición de investigación "A" depende de tres clases de intereses y asunciones compartidos: los que derivan de la cultura en la que se halla inmersa, los que derivan de las tradiciones predecesoras de "A", y los que derivan de "A" misma". De ese modo, el número e importancia de los problemas resueltos por una tradición de investigación no dependerían sólo de los que resultan relevantes para dicha tradición, sino para el conjunto de la disciplina. Los problemas empíricos más destacados serían aquéllos que son responsables de la unidad de la disciplina científica; tales serían los arquetípicos, resueltos o tratados por todas las tradiciones dentro de aquélla. Sobre tal base, propone Doppelt, sería posible construir y ordenar el dominio de problemas más o menos comunes y más o menos importantes de la disciplina como un todo. Ellos definirían, así, ese conjunto de meta-estándares requerido para confrontar tradiciones de investigación en cuanto a capacidad resolutiva de problemas. Por otro lado, sobre tales tipos de problemas generales cabría articular esa acumulación (parcial) de conocimiento que se evidencia en la historia de las disciplinas.

Por ejemplo, cuestiones generales en Geografía, tales como las concernientes a la interacción hombre-medio, diferencias y similitudes en el espacio, localización y distribución espacial de fenómenos, evolución del territorio, comportamiento del hombre en el entorno, naturaleza de los lugares y regiones, etc. conforman la cúspide de la pirámide de problemas, más o menos común a todas las tradiciones ("regional", marxista, humanista, etc.), como más adelante intentaremos poner de manifiesto. Parece evidente que la consideración de ellos entra normalmente a formar parte de modo sustancial en los juicios de evaluación.

B) Una segunda y atinada crítica ha insistido en que Laudan fue demasiado lejos al rechazar la meta de la empresa científica en términos de progreso hacia una creciente verosimilitud o aproximación a la verdad (Newton-Smith, 1981: 195). De la constatación de falsedad de teorías pasadas no se debe

\footnotetext{
9. Del mismo modo, y tras reconocer con Laudan que los problemas conceptuales abordados por las tradiciones de investigación de una disciplina varían mucho en la historia, sugiere que sería preciso posiblemente determinar el conjunto de ellos compartidos por todos los científicos (unos podrían ser "internos" como los de no claridad, inconsistencia, tautología, etc. y otros "externos", como los de incongruencias de las asunciones básicas de una tradición de investigación con las de otra disciplina científica, cosmovisión extracientífica, etc.)
} 
caer en la renuncia a la meta de verdad. Este autor realiza algunas consideraciones, apuntaladas en el sentido común, que sostienen la necesidad de no marginar la noción de verdad en el progreso científico. Resumimos tres de ellas:

- En primer lugar, asumir una concepción agnóstica respecto a la verdad, implica aceptar que nos despreocupamos de cómo el mundo es, por lo que la empresa científica carecería de sentido (id.: 190).

- En segundo lugar, si podemos hacer una apreciación de la racionalidad de creer en cualquier enunciado empírico, ¿por qué no realizar tal apreciación de las teorías que son sólo conjunciones de tales sentencias? (id.: 192)

- Y en tercer lugar, dado que aceptamos las teorías como base para la acción, si no asumimos que la efectividad en la resolución de problemas constituya un cierto apoyo al contenido de verdad de ellas, entonces sería totalmente irracional actuar conforme a una teoría aceptable bajo el modelo de Laudan (id.: 195).

Adicionalmente, y como sostén fundamental de su argumentación, Newton-Smith (1981: 196-197) aduce con acierto una premisa común a todos los autores: dentro de una ciencia madura ha habido una impresionante mejora en el poder predictivo de las teorías. A continuación el autor intenta articular una noción del grado de verosimilitud de las teorías (id.: 198-205), cuyo detalle obviaremos aquí, pero de la que concluye que una teoría con mayor verosimilitud que otra probablemente tiene mayor "éxito en la observación"10. La explicitación de éste último concepto le conduce a aceptar la necesidad de acumulación en el conocimiento, lo que se traduce en dos rasgos: por un lado que la nueva teoría contenga no sólo el apoyo empírico de la anterior sino más, y por otro que ofrezca un mayor éxito en las predicciones.

A nuestrojuicio, puedeaceptarse el segundo rasgo ya que, como reconoce más adelante elautor (id.: 268), resulta la hipótesis que ofrece la mejor explicación del aumento en el poder de predicción y manipulación conseguido por la ciencia; sin embargo, el primero parece más discutible. Dos teorías, T1 y T2, abordando el mismo problema, e.g. el comportamiento espacial de hombre desde distintos ángulos (por ejemplo, desde la óptica económica o desde el conductismo psicológico), y con desigual nivel predictivo podrían no englobar empíricamente una a la otra, es decir, cada una podría contar con un grado de corroboración empírica que sólo en parte fuese común a ambas (figura 1).

Figura 1. Representación del apoyo empírico de dos teorías rivales.

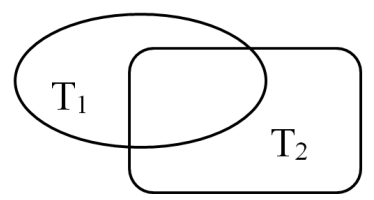

En todo caso, aun aceptando que el atributo de verosimilitud debe ser un componente del entendimiento del progreso científico, parece que se requiere profundizar más en el análisis de este punto.

C) Finalmente, y a nuestro entender, es en la cuestión clave de la evaluación de la efectividad de resolución de problemas por donde puede introducirse un margen de incidencia a los factores externos de cambio científico que se constatan por la sociología e historia de las disciplinas. Qué duda cabe que el juicio evaluador de los científicos se ejecuta según procedimientos plurales; éste puede realizarse de un modo formal (adoptando incluso técnicas sistemáticas para ello), sin embargo, probablemente se actúa muchas veces sin un proceso "riguroso" tal. Lo que parece obvio, sin embargo, es que a las "razones" aducidas, subyacen condicionantes externos (valores, creencias, ... impregnadas de ingredientes éticos, estéticos, religiosos, afectivos, etc.). Por ello, a nuestro juicio, cabría pensar mejor en la noción de "racionalidad limitada" de los científicos ante tal trance. Dadas las restricciones de

\footnotetext{
10 Tal es el criterio que el autor más adelante califica como test último para dilucidar la superioridad de una teoría sobre otra, es decir, para el progreso científico (Newton-Smith, 1981, p. 224).
} 
la mente humana, a las que no escapan la de los científicos ${ }^{11}$, parece más creíble y estimulante, como norma para la conducta investigadora, asumir que las opciones elegidas en materia de conocimiento tienden y toman como referencia esa racionalidad subóptima, puesto que en términos absolutos resulta inalcanzable ${ }^{12}$. En todo caso, ello no entraría en colisión con la concepción de Laudan, ya que desde el momento en que él entiende que el esse (ser) de los problemas es su percipi (percepción), cabe aceptar que esa percepción, individual o colectiva, está mediatizada por factores externos no-racionales.

\subsection{Una breve recapitulación}

La precedente exposición sobre algunos asuntos epistemológicos centrales permite enunciar con cierto fundamento los principales puntos que definirían un entendimiento de la cientificidad pragmáticamente inspirado.

En primer lugar, que la racionalidad científica implicaría dos condiciones básicas: por un lado, que la meta estipulada para la indagación sea científica y no de otro tipo, y por otro, que se han de poseer razones buenas y científicamente respetables para pensar que la opción que se toma (al comparar teorías por ejemplo) es la mejor, como expresó Newton-Smith (1981: 280-281).

En segundo lugar, que resulta aceptable la existencia de varios modelos racionales de ciencia en la historia (llámense paradigmas o tradiciones de investigación), en cuya evaluación, hecha desde nuestro propio horizonte, debe incluirse el propio contexto que definía la racionalidad en tal situación, porque como señaló certeramente Winch (1958) "Los criterios de la lógica no son un don de Dios, sino que surgen de y son inteligibles en el contexto de los modos de vivir o modos de vida social".

En tercer lugar, que el papel de los "factores externos" (sociológicos, psicológicos, etc.) estriba en dar cuenta cómo se forman, en un determinado contexto, las "razones" sustentadoras de las decisiones de los científicos en la evaluación y adopción de teorías y de tradiciones de investigación o paradigmas. Esto es, contribuyen a explicar el marco en el que se inscribe la "racionalidad limitada" asumida aquí para la práctica de los científicos y del hombre en general.

Y en cuarto lugar, que un entendimiento de la ciencia que vincule por un lado la efectividad en la resolución de los principales problemas más o menos compartidos por las distintas tradiciones de investigación de una disciplina y, por otro, una acumulación parcial de conocimiento, un aumento del poder predictivo de las teorías y de la verosimilitud (al menos supuesta) resulta, hoy por hoy, una posición defendible para la ciencia, en general, y para la Geografía, en particular.

Ello, en definitiva, permitiría calificar a esta concepción de racionalista moderada respecto a la empresa científica, porque ésta también está hecha de hombres. Esto es, ni más ni menos, lo que Mario Bunge (1986: 93) expresó paladinamente en un párrafo que puede cerrar nuestra argumentación: "Quienquiera que haya trabajado alguna vez en ciencia sabe que el científico, sea matemático, naturalista o sociólogo, hace uso de todos los mecanismos psíquicos y que no es capaz de controlarlos todos, ni puede determinar siempre cuál ha intervenido en cada caso. En cualquier trabajo científico, desde la búsqueda y el planteo del problema hasta el control de las solución, y desde la invención de las hipótesis-guías hasta su elaboración deductiva, intervienen la percepción de las cosas, acontecimientos y signos; la imaginación o representación visual; la formación de conceptos de diverso grado de abstracción; la comparación que lleva a establecer analogías y la generalización inductiva junto con la loca conjetura; la deducción, tanto formal, como informal; análisis toscos y refinados, y probablemente muchas otras maneras de formar, combinar y rechazar ideas ..."

${ }^{11}$ Barnes (1985, p. 36) apunta el irónico dato de que los científicos no obtienen buenos resultados en los test que exigen un razonamiento abstracto "lógico".

12 No son pocas las posturas articuladas sobre el carácter no enteramente racional de las decisiones de los científicos en materia de conocimiento. Véase, como ejemplo, Thuillier (1975, p. 43 y ss.) quien ejemplifica con el caso crítico de la aceptación o rechazo de teorías. 


\section{ENTENDIMIENTO Y NATURALEZA DE LA PRAXIS CIENTÍFICA GEOTECNOLÓGICA}

Lo expuesto en los apartados anteriores proporciona bases para acometer el objetivo de establecer un entendimiento de la cientificidad en clave geotecnológica, abordando una serie de puntos que permitan sustentar suficientemente esa propuesta. A tal fin se planteará una argumentación que considere como marco epistemológico la concepción de Laudan sobre la ciencia y su evolución, con las ampliaciones y revisiones críticas ulteriores.

Procede de entrada recordar que las geotecnologías engloban al conjunto de conocimientos técnicos, científicamente sustentados, que manejan información geográfica, esto es asociada a coordenadas, y que son aplicables a una amplia gama de actividades. Incorporan un extenso abanico de máquinas (electrónicas particularmente, como los computadores), software y técnicas que soportan funciones de obtención, procesamiento, visualización y difusión de dicha información. Entre las más conspicuas abarcarían la cartografía, los sistemas de información geográfica, la teledetección, los sistemas de posicionamiento global, etc. pero también, e indirectamente, otras que de forma paulatina están pasando de una fase donde manejaban solo información no geográfica a otra en la que tratan geodatos de manera diversa, pero muy notable, e.g. las redes, internet o los terminales de comunicación personal ("teléfonos" móviles en su rica variedad).

Como punto de partida dos cuestiones directas podrían ser suscitadas. En primer lugar, ¿pueden las geotecnologías implicar un cambio tal que den lugar a un entendimiento diferente de la cientificidad geográfica? En ese sentido, se asume aquí la premisa de que la praxis científica geotecnológica puede ser constitutiva de una tradición de investigación en Geografía, equiparable a los paradigmas que se han identificado en esta disciplina (vid. apdo. 2), tal como algún autor ha planteado (e.g. Buzai, 2001, 2011). Ello exige poner de manifiesto que dichas geotecnologías asumen un lugar esencial y determinante en la aparición de ese nuevo proceso cognoscitivo científico, constituyéndose en condición necesaria del mismo.

En segundo lugar, y para completar el planteamiento, cabría interrogarse si el empleo de geotecnologías es condición por sí solo suficiente para calificar una praxis científica como geotecnológica. Nuestra respuesta ahora es negativa. Ello implica reconocer que hay prácticas investigadoras que explotan dichas geotecnologías, pero no de una manera sustancial en el proceso de creación de conocimiento, sino que las usan como meros utensilios accesorios, es decir, que aquéllas jugarían un papel subordinado o si se quiere circunstancial, en cuanto al conocimiento generado. El criterio dirimente no sería tanto la mera cantidad del uso de geotecnologías, sino una diferencia de cualidad: se trataría de aquellos usos como simples herramientas para realizar tareas "mecánicas" o que intervienen secundariamente en el proceso cognoscitivo. Para ilustrar este caso, bastaría aducir aquellas aplicaciones de las geotecnologías orientadas a solventar labores que históricamente se han resuelto de otra manera e. g. la producción rutinaria de mapas temáticos para mostrar ciertos fenómenos, por lo que su papel apenas trasciende el mero fin de la eficiencia en la producción cartográfica. La geotecnologías, singularmente las digitales, podrían claramente ser sustituidas por otros instrumentos o recursos para esos fines (como antaño sucedía), sin que se viese afectado el núcleo del proceso investigador.

En los apartados siguientes se tratará de razonar, en primer lugar, hasta qué punto la tecnología en general, y las geotecnologías en particular, poseen una trascendencia tan profunda en el quehacer científico que implica una forma distinta de investigar y una capacidad resolutiva de problemas superior a la de otras tradiciones de investigación; a continuación se definirá dicha praxis científica, señalando sus elementos diferenciales y genuinos, para luego completar su caracterización señalando sus filosofías inspiradoras y las connotaciones ontológicas que conciernen a los objetos de estudio, sus peculiaridades metodológicas, el tratamiento de los problemas y conceptos geográficos claves, y las metas científicas y sociales del conocimiento generado bajo ese marco.

\subsection{Sobre el alcance gnoseológico de la tecnología}

Plantear que la geotecnología posee un papel tan profundo como el aludido en el título exige sustentar que la forma de indagar científicamente queda modificada de manera sustantiva. La atención que en las últimas décadas está cobrando la filosofía de la tecnología (vid. Méndez, 1989), aparte de subsanar 
un déficit ostensible y sorprendente, dada la trascendencia de ésta última, está aportando luces muy sugerentes sobre la relación ciencia-tecnología.

A tal fin resulta clarificadora y oportuna aquí la discusión de Agazzi (1998) sobre el tema, en la que mantiene la tesis de que "la tecnología es un elemento estructural del conocimiento científico moderno", en el sentido de que su trascendencia alcanza a la concepción del conocimiento como tal. Sus argumentos principales pueden resumirse como sigue.

En primer lugar, la tecnología determina y establece el control teórico de la experiencia. Frente a la observación directa de la realidad, propia de la ciencia (natural) antigua, la ciencia moderna (desde Galileo, Newton y otros) adopta la observación "instrumental". Ello supone que ante un problema a entender, la dilucidación de la hipótesis formulada pasa por construir artificialmente una situación experimental en cuyo seno realizar la comprobación. En palabras del propio autor: "En conclusión, ya en su comienzo la ciencia moderna se revela estructuralmente conectada a la tecnología, pues, en primer lugar, es necesario inventar, construir un instrumento para "observar" la naturaleza; en segundo lugar, el "experimento" científico consiste en la realización de una situación artificial, precisamente porque sólo dentro de una situación artificial se podrá poner a la vista lo que nunca se aprecia en una observación natural. Así, la ciencia experimental es una ciencia que ya, en su acta de nacimiento, lleva escrita la tecnología en sus raíces". Por tanto, la tecnología (condición básica del método experimental) resulta consustancial con este entendimiento de la cientificidad.

En segundo lugar, en el proceso de investigación de la ciencia moderna, la observación para confirmar o falsar, se remite al tribunal experimental, y especialmente, a los resultados de los experimentos. Pero en ellos la tecnología es un elemento básico y no-eliminable de la estructura noética de la ciencia, dado que los experimentos dependen de y se construyen con la tecnología (la cual en este sentido es mucho más que ciencia aplicada, entrando a formar parte de la estructura misma del conocimiento científico). Ese rasgo permite traer a colación el fenómeno - y riesgo - de la "adaptación inversa" según la cual se produce una acomodación de los fines a los nuevos medios técnicos, a las exigencias del nuevo orden tecnológico (Winner, 1977, cit. por Veregin, 1995: 97), por lo que el artefacto (e.g. el ordenador) deja de ser neutral, actuando entonces como filtro o restricción para el desarrollo de un modelo de algunas relaciones supuestas en el mundo real. "El ordenador influye en la forma como los problemas de investigación son seleccionados para su estudio y el carácter de las asunciones, lenguajes, técnicas y modelos aportados para abordar el problema (Veregin, 1995: 96-100). Este rasgo u objeción, que se retomará más adelante, puede tener una lectura alternativa y en clave positiva, por cuanto en ello reside precisamente el empoderamiento de la praxis geotecnológica para resolver problemas. Como aduce García Bacca (1986:91) con el caso de la física-matemática, "son los físico-matemáticos - sobresaliendo entre otros los actuales - los que, real y verdaderamente gigantes han luchado, no a <brazo> partido, sino a <instrumentazos $>$, con la realidad profunda del universo. Con el ser real de verdad.".

En tercer lugar, el conocimiento científico no se ocupa de lo real en su totalidad, sino selectivamente desde unos puntos de vista o conceptos determinados. En este sentido, "la importancia de la tecnología es fundamental, ya que la intervención de la tecnología permite a cualquier ciencia empírica constituir su ámbito de objetos" de estudio (físicos, biológicos, geográficos, etc.) y los resultados de la indagación serían productos ("previsiones") tecnológicamente sustentados en muchas confirmaciones o corroboraciones exitosas.

Y en cuarto lugar, la máquina (i.e. la tecnología) se constituye en criterio de inteligibilidad de las cosas. "La tecnología ha cambiado profundamente la manera de entender la explicación científica. Ésta consiste muy frecuentemente en elaborar un modelo máquina para casi todas las cosas", cuya lógica de funcionamiento es conocida. En lo relativo al proceso de conocimiento científico, es bajo el marco de dicho modelo como lo observado resulta interpretable por parte del experto y encuentra sentido cabal, aunando el conjunto de sus facultades mentales (lo que le permite "ver" de forma más penetrante). En palabras del propio Agazzi (1998): "En conclusión, se puede afirmar que la tecnología es la condición generalizada para la construcción de los objetos científicos y para su conocimiento. ... de la realidad compleja se realiza una especie de corte que selecciona ciertos aspectos a fin de someterlos a los procesos cognoscitivos, y tales aspectos son hoy día los que tan sólo mediante instrumentos de tecnología muy 
avanzada se pueden poner en evidencia. En este sentido se puede afirmar que los objetos son construidos". Por nuestra parte, procede advertir que asumimos estas posiciones de manera parcial por cuanto, sobre las bases de concepción pragmatista expuesta anteriormente, no consideramos que sea ésta la única forma de conocimiento científico.

En resumen, el autor establece con bastante acierto que la tecnología alcanza un protagonismo nuclear en la creación de conocimiento, articulando las funciones intelectuales puestas en juego en la investigación, de manera coherente y eficaz en la resolución de problemas. Al decir, más enjundioso del filósofo García Bacca (Anthropos, 1989: 2), "La tecnología actual ... se fundamenta en una ontología de la creación y de la probabilidad, cuyo sujeto es el <Nos> creador artificial y social. Sus categorías analíticas no pueden ser otras que las de invento, novedad, transustanciación y transfinitación, transmutación continua de límites". La técnica actual nos muestra con eficacia el paradigma de una ontología, antropología y epistemología dialéctica <en realidad de verdad>".

Aceptando esos postulados, procede aclarar ahora cómo el modo de investigar permeado por las TIG concuerda con los mismos, por cuanto ello apuntalaría la tesis de que conforma un cambio drástico en la cientificidad geográfica. A ello se destina el siguiente apartado.

\section{2. ¿Cómo se establecen, formalizan y resuelven los problemas de conocimiento geográfico bajo la praxis científica geotecnológica?}

\subsubsection{Los elementos estructurales de la investigación geotecnológica}

Un examen del proceso de indagación subyacente a conspicuos trabajos realizados bajo esta perspectiva podría reconocer dos momentos iniciales que resultan determinantes del decurso posterior.

En primer lugar, la identidad del problema de conocimiento. Ello concierne a cuestiones que atañen a la individualización del mismo, a sus límites y alcance, a su naturaleza "sensu lato", a su relevancia y a las eventuales utilidades derivables de su resolución. El abordaje de estos asuntos implica unas presunciones acerca de las posibilidades de resolverlo aceptablemente, establecer su trascendencia como incógnita cognoscitiva, clarificar su entidad en el marco de la problemática de la disciplina, legitimar la investigación a partir de las consecuencias y aplicaciones de los resultados, etc. Pues bien, ya en esta fase las TIG juegan un papel trascendental pues aportan una plataforma sustantiva para concretar respuestas a tales cuestiones, en particular, la coherencia del asunto con el prisma o punto de vista disciplinar, las cualidades del problema geográfico dentro del elenco de las preocupaciones de la disciplina, la identificación de los aspectos significativos del mismo (permitiendo así su acotación), la viabilidad de su abordaje (basada en las prestaciones de las TIG), las ventajas derivadas de una resolución eficiente para unos destinatarios (mercados) definidos, etc.

En segundo lugar, la formulación operativa del proceso de resolución. Ello se refiere a preguntas tales como ¿qué procedimiento general se considera aceptable para dilucidarlo?, ¿bajo qué condiciones es abordable y resoluble?, ¿qué instrumentos permiten obtener resultados / respuestas admisibles?, ¿cómo establecer el grado de plausibilidad, y por ende, de aceptabilidad de la "solución"?

Es en este segundo momento cuando, en general, se fijan las bases y mecanismos fundamentales que confieren entidad diferencial y legitimación gnoseológica al proceso ulterior, sea cual fuere la concepción de la cientificidad asumida. Pues bien, escrutando las descripciones realizadas por diversos autores (vid. Buzai y Durán, 1997, cap. 2; Buzai, 1999: 58-61; Schuurman, 2004; Maantay y Ziegler, 2006; Steinberg y Steinberg, 2006; Lloyd, 2008; Parker y Asencio, 2008; Cruz, 2010; Buzai, et al., 2010;) acerca de la indagación con TIG/SIG, es posible constatar que la praxis investigadora geotecnológica implica una serie de entes (la realidad espacial y la digital) y de operaciones mentales (de abstracción, exploración, clasificación, interpretación, trasposición, relación, etc.) que concuerdan netamente con las propuestas de Agazzi (1998). En efecto, y quizá sea lo más importante, el proceso científico ahora implica la construcción de una realidad basada tecnológicamente (mediante lo que se denomina diseño y modelado de la base de geodatos) que supone una trasposición selectiva de la realidad territorial a un cosmos digital, el cual a partir de ese momento suplanta en gran medida a aquélla. Al respecto, leyendo la obra de Tomlinson (2007), 
especialmente el capítulo 9 en el que describe someramente los modelos existentes para el diseño de bases geodatos y (relacional, orientado a objetos y de objetos a bases relacionales), es cuando se puede apreciar meridianamente, no solo en el plano técnico, sino sobre todo noético, el significado más profundo de esa operación y su resultado, que para muchos principiantes o legos puede aparecer como una mera labor técnica desembocando en unos ficheros digitales de datos más o menos complejos. Sin embargo, lo que se genera así es un constructo que constituye una re-creación del mundo real de alcance ontológico, por lo que cabría calificarla más como transustanciación que como simple transformación. La realidad geográfica (RE) se transmuta en realidad digital (RD), sustituyendo ésta a aquélla en el proceso de resolución de problemas de conocimiento. Esa RD no es una recreación completa de aquélla, sino parcial, lo que implica instituir límites a lo observable distintos a los de la RE.

El alcance ontológico de esa labor reside en dos condiciones: a) la realidad digital posee entidad diferenciada de la geográfica, b) la realidad digital posee una estructura y contenidos propios, los cuales se consideran bastantes (en términos de representatividad ${ }^{13}$ ) como para sustentar la racionalidad de la indagación científica sobre ella. Trabajar con fines cognoscitivos en ese entorno tecnológico (máquina, al decir de Agazzi, 1998) calificable como "laboratorio geodigital" o LGD (vid. figura 2) supone asumir que la representación del mundo que contiene es lo suficientemente fidedigna (según el problema tratado) como para habilitar la praxis indagatoria y avalar racionalmente los resultados (sin perjuicio de las validaciones y comprobaciones pertinentes). Como ilustraciones de los avances reales en esa forma de operar podrían señalarse dos: de un lado la visión esbozada por Craglia et al., (2008) de los colaboratorios virtuales como infraestructura para la e-ciencia (e.g. www.accessgrid.org), posibilitando el acceso a geodatos, información, servicios, modelos, escenarios y predicciones geodigitales, sobre la base de estándares compartidos y facilitando el abordaje de problemas y la difusión universal de los resultados; y de otro los mapping mashups (vid. Mateos, 2013) que, como herramientas tecnológicas, viabilizan el acceso a bases de geodatos localizados en servidores múltiples, los cuales son combinados visualmente a medida del usuario en la pantalla de su terminal, para los fines, e.g. investigadores, que desee. Se trata, pues, de una etapa tecnológica nueva, más formalmente estructurada, para soportar esta praxis de indagación.

A partir de ese momento, una gran parte de las principales operaciones de resolución del problema de conocimiento quedan en gran medida confinadas al cosmos digital, sin perjuicio de las labores de comprobación/validación de los resultados (figura 2) con el mundo real (vid. Steinberg y Steinberg, 2006: 63-64). Quizá la expresión más conspicua y aquilatada de ese constructo tecnológico sea la realidad virtual (vid. Fisher y Unwin, 2002) la cual, como Fairbairn y Parsley (1997) señalaron, se conforma como un entorno interactivo de presentación gráfica de información espacial en el que, entre otras cosas, es posible para los usuarios hacer asunciones y comprobar hipótesis. En palabras lúcidas de Suy y Morrill (2004: 98), "the computer has, in the information age, developed into a powerful metaphor for understanding the universe". Este hecho fundamental es el que obliga al investigador a tomar conciencia y valorar con rigor el grado de exactitud (accuracy) e incertidumbre, inherentes a la representación de la realidad espacial o modelo que se habilita en el LGD (vid. Longley et al., 2010, cap. 6).

Planteando las cuestiones de otra manera, cabría preguntarse: en gran medida, ¿no es el LGD quien está estableciendo los límites, no solo de la representación de lo realmente conocido y experimentable, sino también de las posibles soluciones al problema?, ¿no está, por tanto, ese conocimiento (y la cientificidad presumible) supeditado y circunscrito a la representatividad del modelo geodigital y a las operaciones (mentales y técnicas) que el investigador ejecuta sobre el mismo? Nuestra respuesta es afirmativa. Desde una perspectiva crítica eso es precisamente lo que recalcó Veregin (1995: 100) al señalar que "technological constraints affect the nature of the models of geographical phenomena that may be developed and applied in a technological environment". Igualmente, Sui y Morrill (2004: 99) lo respaldaron al decir que "... computer systems can shape our understanding of social or physical reality so that effects are due, not to the phenomena measured, but to the systems measuring it".

\footnotetext{
13 Se asume que el modelo de geodatos posee la calidad suficiente, i. e. que los errores se mantienen en unos niveles admisibles. Por usar un vocablo común en el ámbito legal, cabría decir que la base de datos aceptable para investigar ha sido (explícita o implícitamente) bastanteada.
} 
En esencia, los entes fundamentales implicados en esta praxis cognoscitiva son (figura 2).

- La realidad espacial o geográfica (RE).

- Los modelos geodigitales de la RE, que se reifican en la base de datos geocomputacional.

- Los modelos e instrumentos analíticos y de decisión (cartográficos, descriptivos, explicativos, simulaciones, prescriptivos, de visualización, ...).

- Los resultados y productos tecnológicos que conforman las soluciones "válidas" al problema.

Figura 2. El laboratorio geodigital como mediador entre la realidad y las facultades mentales humanas.

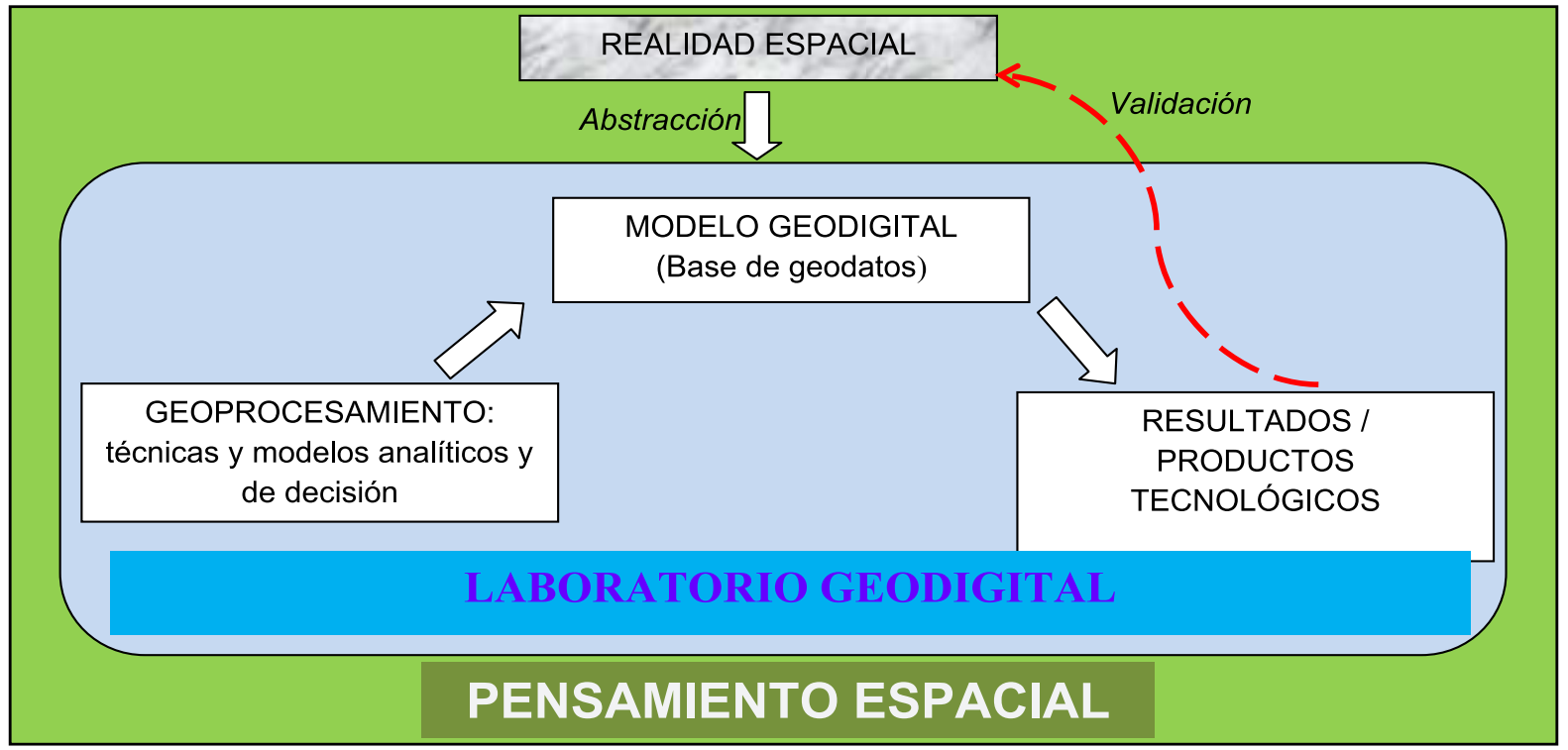

Teniendo todo ello en mente, merece subrayarse muy especialmente un rasgo de esta nueva praxis: el tipo singular de pensamiento espacial ejecutado por el investigador, el cual se halla tan inextricablemente compenetrado con las geotecnologías (el modelo geodigital y las técnicas analíticas sensu lato del LGD) que su génesis y decurso solo es factible e inteligible en este marco experimental.

Procede resaltar al respecto que las operaciones mentales secuencialmente acometen a) la creación (o asunción) de un constructo y b) su análisis, lo que conforma una jerarquía de abstracción conceptual de tipo inclusivo, de suerte que los niveles de especificación posteriores se sostienen comprensivamente sobre los previos, heredando sus propiedades, condiciones y reglas de validez. Es un decurso en cascada que da identidad diferencial a esta praxis cognoscitiva geotecnológica.

Al fin y al cabo, lo importante para esa forma de investigar estriba en que la comunidad científica reconoce y avala que con ella se solventan eficazmente muchos problemas de conocimiento ¿No se está aceptando como válidos (aunque sean temporal u operativamente) los hallazgos, por ejemplo, de la simulación de procesos (e.g. dinámicas hidrológicas, crecimiento urbano, etc.) o la medición de ciertos conceptos (e. g. los riesgos o los impactos ambientales) bajo ese marco?

Resulta conveniente añadir unas consideraciones acerca del fenómeno de "adaptación inversa" sobre el que diversos autores han especulado, en términos negativos, advirtiendo que una praxis como la descrita conlleva "una reorientación de la investigación de suerte que esté más alineada con el nuevo aparato técnico. El estudio de ciertos problemas no susceptibles de automatización, pueden ser abandonados, el estudio de otros puede ser restructurado para un manejo eficiente de datos y nuevos problemas puede ser adoptados centrándose explícitamente sobre cuestiones técnicas" (Veregin, 1995: 97). Aunque tales consecuencias podrían ocasionarse, no parece que la apreciación esos peligros sea muy realista, dado que, al menos en Geografía, la multiplicidad y coexistencia de enfoques o tradiciones de investigación es bien patente (en modo alguno se constata un "monopolio" de la praxis geotecnológica), lo que conjura la primera de las amenazas; y respecto a las dos últimos temores, no deberían considerarse negativos de forma absoluta, sino que precisamente tienen también una cara positiva y, a nuestro juicio, en alto grado. 


\subsubsection{El nuevo papel del pensamiento espacial visual en el LGD}

Dada la trascendencia que en esa praxis geotecnológica adquiere el pensamiento espacial visual resulta útil una breve digresión sobre el mismo y su materialización en ese contexto. La "inteligencia espacial" está bien identificada como facultad humana que nos permite ejecutar operaciones mentales y conductas espaciales para el logro de fines muy diversos (vid. por ejemplo Smith, 1964; Gardner, 2006). Su desarrollo constituye una de las metas en la formación general de los ciudadanos, lo cual significa ejercitación de cara a progresar en diversas competencias. Los mapas constituyen el medio por excelencia para ese perfeccionamiento por cuanto permiten, a través de la imagen visible, mostrar patrones, establecer relaciones, derivar significados, desvelar fenómenos "invisibles" para nuestros sentidos (pero muy reales), etc. Por ello no extraña que la expresión "visual thinking" se haya también usado extensamente, puesto que la comprensión, visualmente sustentada sobre todo, brota de la colaboración de los ojos y el cerebro, a resultas de la cual lo percibido por el ojo se inserta en la trama de conocimiento previo, propiciando su entendimiento e interpretación (Lund y Sinton, 2007: 8).

La importancia de este concepto en la tradición geográfica está bien reconocida, bastando recordar que por parte de diversos autores se postuló que la identidad diferencial de la disciplina como ciencia residía en el particular punto de vista que en ella se adoptaba, el "enfoque geográfico", lo que entre otras cosas, implicaba poseer una mente estructurada convenientemente para aplicarlo. Como un ejemplo de los muchos pronunciamientos en esa dirección puede citarse la idea enunciada hace ya bastantes décadas por Barrows (1931: 353): "El principal fin de la enseñanza de la Geografía no es la información, sino la capacidad de pensar geográficamente".

El punto que induce a traer a colación aquí este asunto estriba en el renovado énfasis que sobre el mismo se ha constatado recientemente, al socaire de la eclosión de las TIG. El posicionamiento decidido del National Research Council (2006b: 1), en un conocido informe por él publicado, era meridiano:

Spatial thinking - a constructive combination of concepts of space, tools of representation, and processes of reasoning - uses space to structure problems, find answers, and express solutions. It is powerful and pervasive in science, the workplace, and everyday life. By visualizing relationships within spatial structures, we can perceive, remember, and analyze the static and dynamic properties of objects and the relationships between objects. ... spatial thinking will play a significant role in the information-based economy of the 21st-century.

A nuestros fines argumentales, quizá lo más significativo estaba en la aseveración que se añadía luego:

... current versions of GIS rate well in terms of their ability to address the three fundamental requirements of a system to support spatial thinking across the curriculum, having the capacity (1) to spatialize data sets by providing spatial data structures and coding systems for spatial and nonspatial data; (2) to visualize by creating multiple forms of representation; and (3) to perform functions by manipulating the structural relations of spatialized data sets (National Research Council, 2006a: 217).

La ancestral prioridad conferida en la disciplina a las representaciones icónicas del espacio (vid. como ejemplo la obra de André et al., 1989) que facilitaban una visualización y reflexión de alcance limitados, ahora, bajo la praxis geotecnológica, adquieren un rol central. No se puede negar que si hay un asunto estrella y fascinante en el panorama actual de las TIG es precisamente el de la geovisualización. La abundante bibliografía generada lo corrobora y los rutilantes resultados y las formidables expectativas de las mismas alimentan la tensión imaginativa sobre innovaciones y aplicaciones (vid. por ejemplo, MacEachren y Fraser Taylor, 1994; Fisher y Unwin, 2002; Bosque y Zamora, 2002; Dykes, et al., 2005; Ojeda, 2010). Definida como el acto de imaginar, "es decir, de ver con imágenes lo que no es normalmente visible" (Cauvin et al., 2008, 175), lo que conduce a generar una representación mental, la geovisualización informatizada ha venido a revolucionar las prácticas de las disciplinas científicas y de muchas actividades humanas. Los neologismos y nuevas expresiones para denotar tales innovaciones (realidad virtual, cibercartografía, globos virtuales, etc.) se han multiplicado. Las dos disciplinas más afectadas en su quehacer, la geografía (que analiza y explica los hechos y procesos físicos y humanos en su espacialidad) y la cartografía, que atiende a las teorías, conceptos y habilidades para representarlos (Harvey, 2008: 6), están afrontando importantes desafíos. La geovisualización involucra dos facetas que conviene recordar (Id.: 9):

- Representación, o proceso de observación y simbolización significativa (con significado).

- Comunicación, que atañe a la presentación del producto y su lectura por los destinatarios. 
Pues bien, de cara a la resolución de problemas de conocimiento, la primera faceta implica a la vez una labor de reflexión experta orientada a desvelar y mostrar visualmente atributos del modelo geodigital (trasuntos de la realidad empírica) que faciliten luego el escrutinio y trabajo por la mente humana sobre lo percibido. De esa manera, los productos de geovisualización, por resultar de ensayos heurísticos con fines indagatorios y por constituir el soporte del ulterior discurrimiento del investigador (e.g. para aceptar o rechazar hipótesis) se configuran como los mediadores críticos del proceso, dado que, el examen de los mismos desemboca en los hallazgos aceptables o rechazables. Esa tarea de pensamiento espacial visual, típicamente iterativa, solo es concebible y fecunda bajo el marco de las prestaciones de las TIG y conforma una de las expresiones más genuinas de su potencia.

Una derivación de esa trascendencia de la geovisualización, relativa a la segunda faceta señalada y que está emanando de las aplicaciones para otros mercados distintos al de las comunidades científicas (e.g. profesionales, políticos, ciudadanos, escolares, etc.), singularmente de aquellas para la planificación, concierne a la "usabilidad" de los productos geodigitales y de visualización de geodatos. Ella resulta crítica para facilitar la materialización efectiva de la participación de los agentes implicados (stakeholders), pues permitiría paliar las dificultades de comprensión y asimilación que algunos de los potenciales agentes participantes poseen, contribuyendo a superar las viejas y excluyentes prácticas de formación de decisiones colectivas sobre el territorio. En esa línea, merece la pena señalar algunas contribuciones destacadas describiendo diversas experiencias como, por ejemplo, las de Kwartler y Longo (2008), Pettit et al., (2008), Aditya (2010) o las incluidas en el número monográfico 25 (2006) del Electronic Journal of Information Systems in Developing Countries.

En síntesis, lo relevante estriba en el reconocimiento de que las TIG sensu lato se han constituido en la condición indispensable para soportar un pensamiento espacial visual potente, eficiente y sagaz de cara a la producción de ciencia, así como para comunicar y formar a ciudadanos cultos y competentes en su vida. Como certeramente aseveraron Buckley et al., 2000: 2):

“...geovisualization" (GVis) ... can be applied to all the stages of problem-solving in geographical analysis, from development of initial hypotheses, through knowledge discovery, analysis, presentation and evaluation.

A mayor abundamiento añadían, citando a otros autores:

"It may be that the greatest contribution of visualization to the process of scientific thinking is liberating the brain from the fundamental activity of information retrieval and manipulation required to produce an image, thereby allowing the brain to devote its time and energy to higher levels of analysis and synthesis" (Id.: 10).

De su trabajo colegían que "Visualization engages, at a deeper level, the cognitive systems of the geographer", opinión que respalda los argumentos blandidos aquí en el apartado previo.

A título ilustrativo puede traerse a colación la obra de Lund y Sinton (2007, cap. 1), quienes de manera concreta, limitada y experimental, se pronuncian de forma determinante sobre ese asunto en el marco escolar, al tiempo que exponen diversos casos en los que se evidenció la decisiva contribución de los SIG como recurso para el desarrollo de habilidades/competencias: la detección de correlaciones espaciales (visuales) desencadenaba la formulación de hipótesis y la apertura de líneas de indagación motivadoras, el descubrimiento y evidencia de patrones (repeticiones, anomalías) conducía a la búsqueda de su significado y posibles causas, el entorno de generación ágil de mapas con SIG alimentaba la producción creativa de nuevo conocimiento al explorar las diversas opciones disponibles (y las perspectivas que ofrecían), etc. En resumen, "con los SIG, los estudiantes tienen la oportunidad de desarrollar destrezas y hábitos de ver y pensar con imágenes ricas informativamente, convertirse en consumidores inteligentes de información visual y en comunicadores eficaces con mapas" (Id.: 15). En otro experimento ejemplar, ahora en el marco universitario, Carbonell et al., (2012) han establecido nítidamente cómo las TIG incrementan de manera significativa ciertas competencias espaciales contempladas en los nuevos grados diseñados según las orientaciones del Espacio Europeo de Educación Superior, aparte de aumentar la satisfacción de los estudiantes. Adicionales experiencias y materiales abundando en esta línea pueden verse en Napoleon y Brook (2008), Oberle et al., (2010) y Luque (2011).

Conviene insistir en que la adquisición de estas habilidades de pensar se constituye en un activo perdurable condicionando las interpretaciones, opiniones, conciencia y conductas de los individuos, por 
lo que sus efectos agregados pueden estimarse decisivos para nuestras sociedades presentes y futuras y sus relaciones con el medio y el territorio.

Establecido ya que las TIG adquieren un alcance gnoseológico en línea con los enunciados de Agazzi, se puede ahora avanzar en la formulación de ciertos aspectos más concretos de la praxis científica basada en ellas.

\subsection{Algunos rasgos del entendimiento geotecnológico de la cientificidad}

El examen de investigaciones genuinas de esta tradición posibilita esclarecer un cierto número de características comunes a ellas, que se presentan a continuación de manera breve.

\section{A) Aspectos epistemológicos}

Resulta bastante claro que el grupo de concepciones positivistas ${ }^{14}$ conforma un antecedente que ha nutrido la praxis científica geotecnológica (vid. Pickles, 1995: 12-15). Asumiendo que las cosas que experimentamos son las que existen, el enfoque geotecnológico adopta, sin embargo, una especial ontología geográfica, es decir, define o concibe las entidades sobre las que recae en última instancia el interés de la pesquisa (lugares, seres vivos, entes y elementos naturales, relaciones, secuencias, eventos, etc.) de un modo propio. Lo fundamental en la realidad empírica no es su significado inmediato, aparente, o contingente, sino aquello que resulta relevante para el objetivo de indagación planteado. Un río o una carretera, al margen de su esencia o su apariencia formal, se han de considerar como entes distintos, según sea el problema de conocimiento. Por ejemplo, para un problema de análisis de flujos podrían transmutarse en entidades (figuras geométricas) lineales, con capacidad para soportar movimientos, etc. A tenor de ello, en la tradición geotecnológica los entes significativos para ser investigados han de ser re-concebidos y recreados como abstracciones teleológicamente fundamentadas, dotadas de propiedades, atributos, relaciones, etc. y, por tanto, susceptibles de ser representadas como artefactos tecnológicos (modelos geodigitales). Bajo tal perspectiva, tanto las manifestaciones de la singularidad, como las comunes a varios entes reales, pueden quedar debidamente recogidas ( $v$. gr. en el dominio de un atributo) y su observación y tratamiento analítico viabilizado. Se justifica así una actitud reduccionista y selectiva ante la realidad, como condición para acceder a un modo de conocimiento que se considera válido. En resumen, lo operativamente investigable es la trasposición geodigital del mundo empírico.

Cabría insistir así en la distinción entre dos realidades, la remota o mediata (la RE) y la próxima o inmediata (la RD), debiendo ser ésta (pueden ser múltiples) una representación bastanteada de aquélla a los fines de conocimiento, puesto que no son equivalentes. Conviene añadir que, dada la naturaleza de este artefacto (modelo), resulta compatible no solo con la representación de atributos (más o menos generales o singulares), sino con otros constructos sobre las dimensiones básicas del espacio o el tiempo, v. gr. los elaborados bajo el denominado paradigma espacial o teórico-cuantitativo (espacio-coste, espaciotiempo, secuencias continuas y discontinuas, etc.). Es decir, en el entendimiento geotecnológico cabría acomodar ontológicamente conspicuos desarrollos realizados bajo el mencionado paradigma.

B) Rasgos metodológicos

Como herencia de planteamientos positivistas y del paradigma espacial, el conocimiento basado en la evidencia verificable y objetiva, asimilable a un acuerdo intersubjetivo (Johnston, 1983: 5) es quizá el que mejor caracteriza la aproximación geotecnológica. Hipótesis científicas, prueba experimental (para verificar o falsar), elaboración de teorías explicativas (Wilson, 1980; Beguin, 1985) y enunciado de generalizaciones constituyen elementos básicos de ese proceder ${ }^{15}$ en cuyo detalle no vamos a descender. Es pertinente resaltar además, por un lado, la subsunción del lenguaje matemático y, sobre todo, de la geometría computacional, en aras de lograr una eficiente trasposición operativa de conceptos y procesos, y por otro, el pujante esfuerzo dedicado a la construcción de modelos para fines múltiples: descriptivos, predictivos, de simulación, de evaluación y prescriptivos, como fórmulas para cubrir las necesidades de

\footnotetext{
${ }^{14}$ Un examen del impacto del positivismo lógico en la Geografía fue ofrecido por Guelke (1978). Gregory (1978, p. 43-73) también le dedicó un amplio análisis.

15 Véanse, por ejemplo, M. Bunge (1980) y Amedeo y Golledge (1975).
} 
experimentación. Recuérdese que la propia naturaleza de las TIG (i.e. el LGD) está constituida en alto grado de herramientas para desarrollar modelos (e.g. los llamados modelos cartográficos) o para aplicar otros muchos prexistentes y concebidos para facilitar la resolución de problemas de conocimiento o de decisión. Los llamados sistemas de apoyo a las decisiones espaciales (SADE) y la geovisualización digital (representando mediante imágenes datos medidos o conceptos y procesos re-expresados numéricamente) son genuinos ejemplos de esta aproximación metodológica. Insistiremos, como rasgo señero, que se trata de modelos (analíticos o de decisión) construidos y aplicados sobre un modelo concreto, pero no único, de la realidad (la base de geodatos digitales), por lo que cabe hablar de un proceso de conocimiento sustentado en un modelado doble.

\section{C) Tratamiento de los problemas claves}

Los conceptos centrales de la disciplina geográfica que se pueden rastrear, aunque bajo formas o enfoques diferentes, en los distintos paradigmas o tradiciones geográficas, subyacen y están presentes en la praxis geotecnológica de forma inequívoca. Chuvieco et al., (2005, 37-38) mostraron con claridad que las tradiciones identificadas como nucleares en la investigación geográfica están presentes en la esencia de las TIG, dando continuidad a las mismas y potenciándolas de manera fecunda. Adicionalmente Buzai (2010) lo ha sostenido de forma harto argumentada: conceptos como los de localización, distribución, asociación, interacción espacial y evolución espacio-temporal siguen siendo las cuadernas del navío "geotecnológico".

En general, el abordaje de los problemas concretos a solucionar implica, como antes se ha dicho, una disección analítica del mundo sustentada en la abstracción del LGD, para desvelar y dar cuenta de ese tipo de cuestiones genéricas, aunque materializadas en facetas concretas de la realidad territorial. Por ejemplo, la diferenciación espacial viene así a ser la resultante de procesos en los que el papel de entes y los factores condicionantes han de estar predefinidos teóricamente y con precisión en el modelo geodigital, posibilitando su aprehensión métrica y visual. La interacción hombre-medio y las asociaciones espaciales aparecen, en general, ampliamente atendidas, merced a la potencialidad de las geotecnologías para profundizar y explorar las relaciones (topológicas y geométricas) que sobre el espacio se pueden producir entre los distintos entes (físico-naturales y humanos), representados por sus correspondientes objetos geodigitales. El tratamiento de la complejidad, y en cierto modo de síntesis "significativas", no queda excluido. La multidimensionalidad de los procesos, las interacciones o los "estados" son abordados bajo los auspicios de la teoría de sistemas, posibilitando la teorización y la simulación experimental a partir de la correspondiente operación previa de abstracción para retener los ítems y relaciones relevantes. La preocupación holista no se margina y puede encauzarse operativa y eficazmente mediante el modelo (selectivo) de geodatos del LGD.

Otro importante componente, el tiempo (y la evolución espacial), queda aprehendido bajo varias conceptualizaciones: bien como un "contenedor" de estados discretos y de secuencias gobernadas por reglas (e. g. estocásticas o deterministas), que generan trayectorias diferentes y conducentes a escenarios diversos (e. g. los trabajos de modelado espacio-temporal con autómatas celulares), bien como una dimensión en la que, al igual que ocurre con el espacio, los sucesos pueden ser "situados" y que impone una fricción o restricciones variables en los procesos (por ejemplo sobre la movilidad, la accesibilidad, la peligrosidad o exposición a amenazas, etc.), bien como constructos con identidad geodigital propia (dotados de atributos, relaciones, etc.), susceptibles de ser geoprocesados (vid. por ejemplo, las propuestas de Maldonado y Vázquez, 2010). Pese a los sugestivos logros alcanzados en el manejo de la dimensión temporal con TIG, cabe todavía atisbar un horizonte fecundo en este terreno.

D) Metas científicas y sociales

El objetivo genérico enunciado por Laudan (1977) para la investigación científica, la búsqueda de soluciones, sería asumible para la praxis geotecnológica, matizando que, sobre todo, se privilegian los problemas empíricos y su lógica teórica. En ese sentido, el entendimiento de la realidad territorial se apoya en generalizaciones explicativas versando sobre patrones, procesos y relaciones espaciales sensu lato. Al obtenerse dichas generalizaciones a partir de modelos de geodatos encerrados en el LGD, los resultados analíticos deberían mostrar un grado aceptable de correspondencia con dichos modelos geodigitales (e.g. los atributos medidos) y también con la realidad, si es posible tal comprobación. No obstante, en 
ocasiones, por tratarse de conceptos o simulaciones imposibles de contrastar empíricamente de forma inmediata por motivos varios, la solución habría de ser considerada como provisional, aunque plausible.

Pero más allá de la creación de ciencia explicativa, la proyección aplicada del conocimiento geográfico ha adquirido un grado de intensidad sin parangón previo en la cientificidad y praxis geotecnológica. Resulta extraordinariamente alta la cifra de estudios de esta tradición en los que el objetivo y consecución de una explotación utilitaria son inmediatos. Frente a otros paradigmas geográficos en los que ese aprovechamiento social era menos patente, se constata que los resultados aplicados gozan de notorio predicamento de cara a la formación y toma de decisiones de planificación o gestión. Usando la distinción recogida por Grimshaw (1994), cabe reconocer que desde las decisiones espaciales de carácter operativo, pasando por las de tipo táctico, hasta las de alcance estratégico, todas ellas han mostrado una receptividad inequívocas a las potencialidades del saber geotecnológico. Es posible afirmar que actualmente las utilidades y el papel económico del saber geográfico, de estar antaño muy circunscritos a las actividades académico-formativas, están ahora cada vez más proyectados hacia sectores y actividades fuera del marco de la educación: descripción, medición, clasificación, prognosis, prescripción, decisión y evaluación o control, basados en geoinformación y tecnologías geodigitales, son funciones que cada vez más están siendo apreciadas y rentabilizadas por organizaciones y ciudadanos, a los que aportan un valor añadido diferencial y notable.

\subsection{Sobre la capacidad de resolución de problemas geográficos bajo la tradición de investigación geotecnológica}

Como en el apartado 4 se apuntó, explicar y apoyar la dinámica temporal de los cambios científicos, i.e. la emersión de nuevos paradigmas o tradiciones de investigación, en la capacidad para solventar más y mejor problemas de conocimiento desemboca en una dificultad métrica importante, la de contar con una contabilidad fiable de ello. Sin negar esa objeción, que requeriría un escrutinio y estudio formal ad hoc, procede realizar algunas consideraciones que, aunque provisionalmente, avalen esa premisa.

Por un lado, no son pocas las afirmaciones contundentes que se han vertido en esa dirección por parte de los estudiosos que han desarrollado investigaciones empíricas con TIG y, por tanto, conformes y ajustadas, en mayor o menor grado, al paradigma o tradición de investigación aquí defendido. En efecto, resulta ya casi una conclusión tópica, por reiterada, que las TIG se muestran extraordinariamente poderosas para solventar problemas de indagación y, si ese consenso entre amplios sectores de la comunidad científica se admite como crédito, entonces estaríamos ante un aval de la superioridad de la praxis investigadora cimentada en las geotecnologías respecto a otras; ello no se proclama aquí a título universal, pero sí para ciertas categorías de problemas geográficos sobre los que más adelante se tratará.

Pese a la limitación que el argumento de autoridad tiene en este contexto, no dejan de ser de interés los pronunciamientos de algunos reputados geógrafos, que además no han sido especialmente adeptos a las TIG. Glosaremos algunos de ellos. Así por ejemplo, el estadounidense Wilbanks (2004: 4) señaló que "technology is an enabler, not a solution", con lo que reconocía su poder, pero implícitamente lo reducía al provisto por una herramienta que capacita, cual si fuese una palanca. Llevaba razón, a nuestro juicio, al afirmar que la tecnología no es la solución, pues ésta solo se puede establecer con la concurrencia de la mente humana y no reside fuera de ella, requiriendo un consenso en la comunidad científica. Lo que olvidó dicho autor fue matizar que la tecnología inequívocamente forma parte (y no menor) de la solución a los problemas. Esa capacidad para arribar a soluciones cuadra a las TIG a la perfección, pues éstas adquieren el nivel de condición sine qua non para un progreso científico calificable de muy fecundo e incluso de espectacular. Gómez Mendoza (2000), por su parte, afirmó, refiriéndose a los SIG, que con ellos “... podemos ver más lejos y profundamente que antes, cartografiar más de lo que está presente en el espacio, plantearnos preguntas antes inimaginables, simular y predecir las distribuciones y modelos futuros. Los SIG proporcionan al geógrafo los nuevos ojos que el microscopio y el telescopio proporcionaron al biólogo y al astrónomo. Siempre que hagamos las preguntas adecuadas y sepamos servirnos de ellos." Tales asertos evocan concordancias implícitas con el pensamiento de Agazzi, y una cierta dependencia de la ciencia a la tecnología. No obstante, las menciones a algunos instrumentos y a sus capacidades alinean a la autora con la corriente que sitúa a las TIG como meras herramientas. Falta aún en los dos 
autores citados el descubrimiento de que las TIG no se quedan en el papel de la herramienta para observar o medir la RE, sino que la recrean (el constructo) e imponen un marco cognitivo singular y distinto (el LGD), que cambia las bases del trabajo científico, tal como hemos reiterado aquí.

Naturalmente el aval más sólido hacia la superioridad resolutiva de problemas de la indagación basada en TIG debería provenir de varias evidencias: la creciente cantidad y calidad de los productos de investigación a los que permea, la considerable aparición de publicaciones periódicas y monografías científicas especializadas, el ingente impacto económico y social que están ocasionando las aplicaciones de las TIG, etc. Obtener indicadores fiables de algunos de esos aspectos no resulta a veces tarea fácil, aunque para otros los indicios y pruebas, pese a ser incompletos o cualitativos, parecen claros.

Pendiente de realizar la oportuna recopilación de datos rigurosos sobre tales logros, que en conjunto justifican el nacimiento de ese nuevo paradigma o tradición de investigación, solo querríamos añadir una breve acotación y ejemplificación final acerca de los tipos de problemas que bajo esta perspectiva se están abordando eficazmente. En una clasificación sumaría aparecen: a) viejos problemas, ahora conceptualizados y solventados de manera nueva o más rigurosa: $e$. g. análisis de patrones espaciales de muchos fenómenos o entes, tales como población (e.g. Cos, 2004), incendios (e.g. Ordóñez et al., 2011), etc. desvelando su distribución espacial, segregación, concentración, exposición, interacción, etc.; estimación de atributos espaciales a partir de muestreo (e.g. la calidad de las aguas subterráneas en Chica et al., 2005; la demanda de transporte de metro en Cardozo et al., 2010); impacto de inversiones territoriales en infraestructuras de transporte (Gutiérrez Puebla, 2005); accesibilidad espacial a equipamientos (e.g. Prat et al., 2009); cambios en usos del suelo (Aldana y Bosque, 2008); seguimiento de procesos (e.g. Romero y Montes, 2009). En ellos las novedades aportadas en el marco de la praxis geotecnológica pueden concernir tanto a la escala o resolución espacial y al tamaño del ámbito considerado (desde el microgeográfico hasta el global), como al conjunto de factores / variables examinados y al propio enunciado y representación conceptual del problema, factible ahora de forma más penetrante o rigurosa; b) problemas nuevos, es decir, apenas o nada tratados anteriormente, y que se han hecho asequibles y manejables merced a las TIG: simulaciones de procesos complejos de carácter urbano (Aguilera, 2006; Plata et al., 2010; Gómez y Rodríguez, 2012) o ambiental (Paegelow y Camacho, 2008); realidad virtual, mediciones de conceptos elusivos tales como peligros naturales complejos (Etxebarría et al., 2005) o de inundación (Varni et al., 2006), riesgos tecnológicos (Bosque et al., 2004), vulnerabilidad territorial (Ruiz, 2012) o costera (Ojeda et al., 2009), fragilidad ambiental (Cabral et al., 2011), justicia espacial o ambiental (Moreno, 2007; Moreno y Cañada, 2007; Cañada et al., 2011), etc.; c) problemas de formación de decisiones espaciales en los que las TIG actúan no solo como proveedoras de soluciones o alternativas de actuación tras los análisis oportunos (e. g. Bosque y Moreno, 2004; Gómez y Barredo, 2005; Lamelas, 2009; Fuenzalida, 2011; Moreno et al., 2012), sino como cauce para facilitar una superior participación de los agentes implicados en el asunto (vid. infra).

En esta parcela cabe reconocer sin ambages que el crecimiento numérico de las aplicaciones podría calificarse de explosivo. En ella es posible distinguir dos tipos de estudios, según apunten a actividades de planificación o de gestión. A nuestro entender, podría aceptarse que el valor añadido, en términos cognoscitivos, sea unitariamente mayor en las aplicaciones de ordenación que en las de gestión, en el sentido de que aquéllas suponen el tratamiento de casos singulares, requiriendo un abordaje y análisis específicos (propios de las decisiones estratégicas), en tanto que en éstas últimas su frecuente mayor simplicidad y rutinización (decisiones operativas) revelarían un menor insumo cognoscitivo. Ello no obstante, conviene recordar que también en este frente, al menos en la fase experimental inicial, la resolución del problema genérico suele haber exigido un esfuerzo indagatorio significativo.

En efecto, si recordamos someramente las exigencias que conllevan los planes de ordenación territorial, urbana, rural, ambiental o un plan estratégico empresarial (e.g. plan de geomárketing), no cabe duda que el equipo elaborador, por un lado, ha de afrontar cuestiones harto difíciles y mal definidas, y por otro, que las TIG, según la experiencias conocidas, están contribuyendo a abordar las complejidades de este tipo problemas de forma mucho más profunda y conveniente que antes. Las referencias, incluso autocríticas, sobre las TIG y la planificación no dejan la menor duda al respecto (vid. por ejemplo, Charlton y Ellis, 1991; Innes y Simpson, 1993; Stilwell et al., 1999; Brail, 2008) y, como bien muestra Escolano (2010), los SIG 
quedan involucrados en la mayoría de las fases de un plan. A mayor abundamiento, las aportaciones sobre participación ciudadana apoyada en SIG ("participatory GIS", PGIS, en la expresión inglesa), pese a los obstáculos detectados, están vislumbrando horizontes novedosos de cara a lograr un funcionamiento más correcto de los mecanismos colectivos de decisión territorial (vid. Craig et al., 2002; Chambers, 2006; Elwood, 2006; Rambaldi et al., Sieber, 2006; 2006; Toudert y Bringas, 2010). En ese sentido, las TIG y los expertos participantes pueden constituir palancas coadyuvantes de cambios en los procedimientos hacia un estadio de superior corresponsabilidad y empoderamiento ciudadano y, por extensión, de calidad democrática, cuestionando la continuidad de aquellas formas tradicionales de tramitación de planes que se limitaban a insuficientes y poco eficaces procesos de exposición y alegaciones públicas.

En labores propias de gestión son muchos y muy conocidos los ejemplos referibles de cómo las TIG están resolviendo tareas operativas que requieren de información geográfica como insumo esencial. Las industrias de software y consultoras de geotecnologías han identificado ingentes posibilidades de negocio al respecto. Baste recordar la creciente gama de servicios basados en la localización, la gestión de rutas (de reparto / recogida), el control de flotas y móviles, la gestión de servicios de emergencias, la recogida, alerta e información a los ciudadanos sobre cuestiones ambientales, el monitoreo de actividades agrarias, extractivas, la información turística, etc. En muchos de ellos, cabe reconocer la indisoluble unidad conformada entre el contenido de geoinformación y la geotecnología, para poder lograr un tratamiento del problema de actuación, superior desde muchos puntos de vista a las prácticas anteriores.

Finalmente, y más como respaldo confirmatorio a posteriori de esa superior efectividad en la resolución de problemas inherente a este paradigma, cabe recordar que si no fuese así, la creciente demanda de conocimiento geográfico y de geotecnologías para aplicaciones fuera del ámbito científico (con su corolario en la importante empleabilidad de los expertos en esos saberes) y por parte de otras disciplinas sería inconcebible. Esa mayor potencialidad, que se está trasfundiendo también a otros campos del saber (historia, arqueología, filología, economía, sociología, ingenierías, etc.) expresa, como bien han dicho Buzai $(2001,42)$ y Torrens (2010), que estamos ante un paradigma geográfico de proyección interdisciplinar y desvela porqué esta nueva praxis está gozando de tanto predicamento y pujanza.

\section{BALANCE Y CONCLUSIÓN}

Existe un elevado consenso acerca del trascendental impacto de las geotecnologías en la ciencia geográfica y, a su través, en otras muchas disciplinas. Sin embargo esa conciencia a menudo se circunscribe a una apreciación limitada por cuanto considera dichas geotecnologías como meras herramientas, potentes eso sí, que incrementan espectacularmente la eficiencia y productividad del investigador, tal como en su día hicieron las calculadoras electrónicas de bolsillo.

Una visión distinta es la que algún autor ha postulado, y que aquí se ha sostenido también, según la cual las transformaciones del proceso de generación de conocimiento geográfico basado en geotecnologías son de tal calado que poseen rango epistemológico, es decir, que implican un entendimiento y una praxis indagatoria nueva y esencialmente distinta de otras que existen y han existido en Geografía. Esas concepciones de la cientificidad, bien identificadas y caracterizadas en diversas obras, responden a unas premisas generales comunes: que la racionalidad de la ciencia es limitada y que los cambios en esos entendimientos suponen una remoción del marco básico de creencias y normas epistemológicas y metodológicas consideradas como válidas en la investigación.

Asumiendo esa forma de relativismo limitado que habilita para comprender la historia de las ciencias, entre ellas la geográfica, en esta contribución se ha partido del pragmatismo epistemológico propuesto por Laudan y ampliado críticamente por otros autores, como sustrato filosófico legitimador de la diversidad de entendimientos de la cientificidad, que autores como Khun o Lakatos plantearon bajo las denominaciones de paradigmas, programas de investigación o, como dicen los pragmatistas, tradiciones de investigación. Esta última doctrina propone, como clave del quehacer científico, una meta muy plausible: la de resolver problemas de conocimiento, dentro del marco de racionalidad limitada característico de toda acción humana. A la par, su aceptación de la coexistencia de diversas cientificidades, avala las propuestas de los epistemólogos de la tecnología sustentando un entendimiento de la misma que trasciende a su consideración como mero instrumento. 
Sobre tales bases se ha intentado aquí argumentar cómo la integración de las geotecnologías en la actividad investigadora está desencadenando un cambio que afecta, no solo al plano metodológico, sino que involucra al nivel gnoseológico del sujeto cognoscente en muchos trabajos de investigación con TIG. En efecto, como las clarificadoras consideraciones de Agazzi y otros filósofos de la tecnología proponen, la moderna ciencia geográfica sustentada en TIG es absolutamente dependiente de éstas por cuanto mediante ellas (condición sine qua non) se configuran los objetos cognoscibles y se establecen las condiciones de inteligibilidad y de abordaje, así como los límites y las posibles soluciones del problema. En síntesis, presuponen una alteración profunda en las creencias, reglas y métodos que rigen y legitiman la labor del científico. Por ello cabe reiterar que, como sucede en otras disciplinas, se trata de un cambio en la Geografía que posee un alcance epistemológico, asimilable por tanto a un nuevo paradigma o tradición de investigación. La mediatización del conocimiento a una trasposición de la realidad territorial a la digital y el proceso mental ulteriormente desarrollado dentro de lo que hemos calificado como laboratorio geodigital (LGD), cimentado en una potente y rica batería de técnicas y tecnologías, son quizá los rasgos más conspicuos de este nuevo entendimiento de la cientificidad geográfica y de su praxis, el cual manteniendo la consistencia con otras tradiciones de investigación, por cuanto acomete las permanentes y grandes cuestiones centrales del núcleo disciplinar, presenta otros hechos diferenciales relevantes, por ejemplo, en cuanto métodos, tipos de problemas concretos prioritarios o metas "estratégicas". Cabría advertir que en modo alguno se ha postulado que las TIG sensu strictu "sean" una nueva tradición de investigación o paradigma, sino más bien que, merced a ellas, en la Geografía está emergiendo uno nuevo, que coexiste con otros más tradicionales.

A lo anteriormente dicho habría que agregar la extendida convicción acerca de su efectividad superior a la de otros paradigmas al tratar ciertos problemas concretos de conocimiento, algunos antiguos (y reformulados), otros nuevos, inéditos y antes intratables, brotados precisamente dentro de las fronteras de este marco epistemológico, lo que viene a acreditar esa potencialidad. El reconocimiento de ello se constata, por un lado en las propias comunidades científicas (y no solo en la de los geógrafos, sino también en las de otras muchas disciplinas) y, por otro, entre los colectivos de decisores (públicos y privados) de todas clases, las organizaciones y los ciudadanos en general, entre los que el saber geográfico, producido y diseminado merced a las TIG, está conquistando un papel vital, con el consiguiente aprecio y revalorización. Como algunos autores han afirmado (e.g. Buzai, 1999: 178-184; Buzai, 2007; Torrens 2010: 134-135) y se ha sostenido aquí también, las TIG han implicado un reposicionamiento del conocimiento geográfico no solo en el concierto de la cientificidad y de las disciplinas académicas, al evidenciarse una prominente contribución a ellas, sino también en el de las aplicaciones útiles, que crecen en una infinidad de campos de la vida y actividades humanas.

Ello es, a fin de cuentas, lo que hoy por hoy está auspiciando un éxito sin precedentes a esta praxis, y a las diversas disciplinas y multitud de expertos que usan las TIG para hallar respuestas y soluciones a problemas de conocimiento y de acción espacial. Mirando retrospectivamente hoy podemos afirmar que el esfuerzo de muchos estudiosos, que en las pasadas décadas pusieron las bases conceptuales, metodológicas y tecnológicas de las TIG tal como hoy las conocemos, resultó decisivo, pero que el devenir de las innovaciones en este terreno permite vislumbrar horizontes futuros muy fecundos para una cientificidad geotecnológicamente instituida como ésta.

Como declaración final, y siendo consecuentes con la aceptación que aquí se ha hecho de la coexistencia de distintos entendimientos de la cientificidad geográfica, resulta procedente, tras la argumentación expuesta, recordar las templadas palabras de Sui y Morrill (2004: 98-99) cuando advirtieron de la existencia de límites en la computación, aduciendo que hay aspectos del universo no computables. Pese a sus demostrados poderes, cabe sostener que la complejidad de la realidad geográfica no resulta representable totalmente y de forma adecuada con la tecnología actual, aunque sí puedan serlo muchos de los rasgos considerados como más relevantes. Tratar de encapsular o encerrar la integridad de los fenómenos geográficos en el ordenador nos sigue pareciendo bastante quimérico. Por tal motivo, la preocupación por los peligros de la "adaptación inversa" no debiera obsesionar a nadie; más aún, precisamente las críticas a la praxis geotecnológica desde ese lado servirían para detectar sus límites y espolear nuevas invenciones para abordar asuntos mal tratados, ... coadyuvando al progreso científico. 


\section{BIBLIOGRAFÍA}

ADITYA, T. (2010): "Usability issues in applying participatory mapping for neighborhood infrastructure planning", Transactions in GIS, 14(S1), pp. 119-147.

AGAZZI, E.:

- (1996): "Racionalidad y ciencia para el futuro del ser humano", Contrastes: Revista interdisciplinar de filosofía, 1, pp. 7-18. http://www.uma.es/contrastes/pdfs/001/Contrastes001-02.pdf

- (1998): "El impacto epistemológico de la tecnología", Argumentos de razón técnica: Revista española de ciencia, tecnología y sociedad, y filosofía de la tecnología, 1, pp. 17 - 32.

http://www.argumentos.us.es/numerol/agazzi.htm

AGUILERA BENAVENTE, F. (2006): "Predicción del crecimiento urbano mediante sistemas de información geográfica y modelos basados en autómatas celulares", GeoFocus (Artículos), 6, pp. 81-112.

ALDANA DEZZEO, A. y BOSQUE SENDRA, J. (2008): "Cambios ocurridos en la cobertura/uso de la tierra del Parque Nacional Sierra de la Culata. Mérida-Venezuela. Período 1988-2003", GeoFocus (Artículos), 8, pp. 139 - 168.

AMEDEO, D. y R. GOLLEDGE (1975): An introduction to scientific reasoning in geography. New York, John Wiley and Sons.

ANDRÉ, Y., BAILlY, A., FERRAS, R., GUÉRIN, J.P. y GUMUCHIAN, H. (1989): Représenter l'espace. L’imaginaire à l'école. París, Anthropos.

ANTHROPOS (1989): "Editorial", 94-95, pp. 2 -3.

BARNES, T. J. (1988): "Rationality and relativism in economic geography: an interpretive review of the homo economicus assumption", Progress in Human Geography, 12, 2, pp. 473-496.

BARROWS, H.H. (1931): "Some critical problems in teaching elementary geography", The Journal of Geography, XXX, pp. 353-364.

BEGUIN, H. (1985): «La théorie dans la démarche de la géographie», L'Espace Géographique, 1, pp. 65 - 68.

BERNAL, J. D. (1972): Historia social de la ciencia. La ciencia en la historia. Barcelona, Península.

BERRY, B. J. L., GRIFITH, D. y TIEFELSDORF, M. R. (2008): "From Spatial Analysis to Geospatial science", Geographical Analysis, 40, pp. 229 - 238.

BOSQUE SENDRA, J., DÍAZ CASTILLO, C., DÍAZ MUÑOZ, M. A., GÓMEZ DELGADO, M., GÓNZALEZ FERREIRO, D., RODRÍGUEZ ESPINOSA, V.M., SALADO GARCÍA, M.J. (2004): "Propuesta metodológica para caracterizar las áreas expuestas a riesgos tecnológicos mediante SIG. Aplicación en la Comunidad de Madrid", GeoFocus (Artículos), 4, pp. 44 - 78.

BOSQUE SENDRA, J. y MORENO JIMÉNEZ, A. (2004, Eds.): Sistemas de información geográfica y localización óptima de instalaciones y equipamientos. Madrid, RA-MA. Segunda edición ampliada y revisada, 2012.

BOSQUE SENDRA, J. y ZAMORA LUDOVIC, H. (2002): "Visualización geográfica y nuevas cartografías", GeoFocus, 2, pp. $61-77$.

BRAIL, R. K. (2008): Planning support systems for cities and regions. Cambridge (Massachusetts), The Lincoln Institute of Land Policy.

BROC, N. (1969): «Peut-on parler de géographie humaine au XVIIle siècle en France?», Annales de Géographie, 78. pp. 57 - 76.

BUCKLEY, A., GAHEGAN, M. y CLARKE, K. (2000): Geographic visualization as an emerging research theme in GIScience. A proposal for adoption of this theme by members of the UCGIS community. 2000 Research White Papers. University Consortium for Geographic Information Science. 13 p. http://dusk.geo.orst.edu/ucgis/web/emerging/Geographic visualization.pdf 
BUNGE, M:

- (1969): La investigación científica. Barcelona, Ariel

- (1978): "Metateoría”, en Bar-Hillel, Y. et. al. (ed.): El pensamiento científico. Conceptos, avances, métodos. Madrid, Tecnos-UNESCO, pp. 225 - 265.

- (1980): Epistemología. Barcelona, Ariel.

- (1986): Intuición y razón. Madrid, Tecnos.

BUTTIMER, A. (1980): Sociedad y medio en la tradición geográfica francesa. Barcelona, Oikos Tau.

BUZAI, G. D.:

- (1999): Geografía global. El paradigma geotecnológico y el espacio interdisciplinario en la interpretación del mundo del siglo XXI. Buenos Aires, Lugar Editorial.

- (2001): "Paradigma Geotecnológico, Geografía Global y CiberGeografía, la gran explosión de un universo digital en expansión", GeoFocus (Artículos), 1, pp. 24 - 48.

- (2007): "Dilemas de la relación Geografía-SIG entre la disciplina, la interdisciplina y la transdisciplina", GeoFocus (Editorial), 7, pp. 5- 7.

- (2010): "Análisis espacial con sistemas de información geográfica: sus cinco conceptos fundamentales", en Buzai, G. D (ed.): Geografía y sistemas de información geográfica. Aspectos conceptuales y aplicaciones. Luján, GESIG- Universidad Nacional de Luján, pp. 163 - 195.

- (2011): "La geotecnología: ¿Nuevo paradigma de la geografía o paradigma geográfico de la ciencia?”, Revista Catalana de Geografía, XVI, 42, 10 p. www.rcg.cat/articles.php?id=187

BUZAI, G.D. BAXENDALE, C. y CRUZ, M.R. (2010): "Fases de un proyecto de investigación en estudios de geografía aplicada basados en el uso de sistemas de información geográfica", en Buzai, G. D. (ed.): Geografía y sistemas de información geográfica. Aspectos conceptuales y aplicaciones. Luján, GESIG - Universidad Nacional de Luján, pp. 197 - 216.

BUZAI, G. D. y DURÁN, D. (1997): Enseñar e investigar con sistemas de información geográfica. Buenos Aires, Troquel.

CABRAL, J.B. P., DA ROCHA, I. R., MARTINS, A. P., DA ASSUNÇÃO, H. F. e BECEGATO, V.A. (2011): "Mapeamento da fragilidade ambiental da bacia hidrográfica do Rio Doce (GO), utilizando tecnicas de geoprocessamento", GeoFocus (Artículos), 11, pp. 51 - 69.

CAÑADA TORRECILLA, R., VIDAL DOMÍNGUEZ, M. J. y MORENO JIMÉNEZ, A. (2011): “Interpolación espacial y visualización cartográfica para el análisis de la justicia ambiental: ensayo metodológico sobre la contaminación por partículas atmosféricas en Madrid”, GeoFocus (Artículos), 11, pp. 118-154. http://geofocus.rediris.es/2011/Articulo6_2011.pdf

CAPEL, H.:

- (1981): Filosofía y ciencia en la geografía contemporánea. Una introducción a la Geografía. Barcelona, Barcanova.

- (1987): Geografía humana y ciencias sociales. Una perspectiva histórica. Barcelona, Montesinos.

- (2010): "Geografía en red a comienzos del Tercer Milenio. Por una ciencia solidaria y en colaboración", Scripta Nova. Revista Electrónica de Geografía y Ciencias Sociales. [En línea]. Barcelona: Universidad de Barcelona, 1 de febrero, vol. XIV, no 313. http://www.ub.es/geocrit/sn/sn-313.htm.

CARBONELL CARRERA, C., MEjÍAS VERA, M. A., SAORÍN, J. L. y CONTERO GONZÁLEZ, M. (2012): "Infraestructuras de datos espaciales: desarrollo de habilidades espaciales en el entorno del Espacio Europeo de Educación Superior", Boletín de la Asociación de Geógrafos Españoles, 58, pp. 157 - 175.

CARDOZO, O.D., GUTIÉRREZ PUEBLA, J. y GARCÍA PALOMARES, J.C. (2010): "Influencia de la morfología urbana en la demanda de transporte público: análisis mediante SIG y modelos de regresión múltiple", GeoFocus (Artículos), 10, pp. 82 - 102.

CAUVIN, C., ESCOBAR, F. y SERRADJ, A. (2008): Cartographie thématique 5. Des voies nouvelles à explorer. París, Hermes Science y Lavoisier. 
CHALMERS, A. F. (1984): ¿Qué es esa cosa llamada ciencia? Madrid, Siglo XXI.

CHAMBERS, R. (2006): "Participatory mapping and geographic information systems: Whose map? Who is empowered and who disempowered? Who gains and who loses?", Electronic Journal on Information Systems in Developing Countries 25(2), pp. 1 - 11. http://www.ejisdc.org/ojs2/index.php/ejisdc/article/view/237/158

CHARLTON, M. y ELLIS, S. (1991): "GIS in planning", Planning Outlook, 34 (1), pp. 20 - 26.

CHICA-OLMO, M., CARPINTERO-SALVO, I., GARCÍA-SOLDADO, M.J., LUQUE-ESPINAR, J.A., PARDO IGÚZQUIZA, E. y RIGOL SÁNCHEZ, J.P. (2005): "Una aproximación geoestadística al análisis espacial de la calidad del agua subterránea", GeoFocus (Artículos), 5, pp. 79-93.

CHUVIECO, E., BOSQUE, J., PONS, X., CONESA, C., SANTOS, J. M., GUTIÉRREZ PUEBLA, J., SALADO, M.J., MARTÍN, M.P., DE LA RIVA, J., OJEDA, J. y PRADOS, M.J. (2005): “¿Son las tecnologías de la información geográfica parte del núcleo de la Geografía", Boletín de la Asociación de Geógrafos Españoles, 40, pp. 35 - 55.

CLAVAL, P.:

- (1974): Evolución de la geografía humana. Barcelona, Oikos Tau

- (1984): Géographie humaine et économique contemporaine. París, PUF (trad. esp.: Geografía humana y económica contemporánea. Barcelona, Akal, 1987, 456 p.).

COMPTE, I., GUIMET, J. y WACHOWICZ, M. (2009): La Sociedad de la (Geo)Información, Revista Novatica, $\mathrm{n}^{\circ} 198$, pp. 6 - 10.

COS GUERRA, O. de (2004): "Valoración del método de densidades focales (Kernel) para la identificación de los patrones espaciales de crecimiento de la población en España", GeoFocus (Artículos), 4, pp. 136 - 165

COUCLELIS, H. (1982): "Philosophy in the construction of geographic reality", en P. Gould y G. Olsson (Ed.): A search for a common ground. Londres, Pion, pp. 105 - 138.

CRAGLIA, M., GOODCHILD, M. F, ANNONI, A., CAMARA, G., GOULD, M., KHUN, W., MARK, D., MASSER, I., MAGUIRE, D., LIANG, D. and PARSONS, S. (2008):" Next-Generation Digital Earth. A position paper from Vespucci Initiative for the Advancement of GIS Science", International Journal of Spatial Data Infrastructure Research, 3, pp. 146-176.

CRAIG, W.J., HARRIS, T.M. y WEINER, D. (2002, eds.): Community participation and geographic information systems. London, Taylor and Francis.

CRUZ, M. R.: "Sistemas de información geográfica y proceso de investigación científica. Sus semejanzas a partuir de las operaciones de disección y síntesis", en Buzai, G. D. (Ed.): Geografía y sistemas de información geográfica. Luján, GESIG-Universidad Nacional de Luján, pp. 65-81.

DOPPELT, G. (1983): "Relativism and recent pragmatic conceptions of the scientific rationality", en N. Rescher ( Ed.): Scientific explanation and understanding. Lanham, University Press of America, pp. $106-142$.

DURBIN, P. T. (1989): "Ciencia y tecnología en su contexto", Anthropos, 94-95, pp. 50 - 56.

DYKES, J., MACEACHREN, A.M. and KRAAK, M.J. (2005): Exploring geovisualisation. Elsevier, Amsterdam.

ELWOOD, S. (2006): "Critical issues in participatory GIS: Deconstructions, reconstructions, and new research directions", Transactions in GIS, 10, pp. $693-708$.

ESCOLANO, S. (2010): "La ordenación del territorio y las nuevas tecnologías de la información geográfica", en Bielza, V., Escolano, S., Gorría, A. e Ibarra, P.: De la ordenación a la planificación territorial estratégica en el ámbito regional-comarcal. Zaragoza, Prensas Universitarias de Zaragoza, pp. 53 - 72.

ESTÉBANEZ, J. (1982): Tendencias y problemática actual de la geografía. Madrid, Cincel.

ETXEBERRÍA RAMÍREZ, P., EDESO FITO, J. M. y BRAZAOLA ROJO, A. (2005): "Metodología para crear mapas de peligros naturales en Guipúzcoa utilizando SIG”, GeoFocus (Artículos), 5, pp. 250 - 267. 
FAIRBAIRN, D. y PARSLEY, S. (1997):"The use of VRML for cartographic presentation", Computers and Geosciences, 23, $475-481$.

FEYERABEND, P. (1974): Contra el método. Barcelona, Ariel.

FISHER, P. y UNWIN, D. (2002, Eds.): Virtual reality in Geography. Londres y Nueva York, Taylor and Francis.

FRANK, A. U.: (2003): "El mercado europeo de información geográfica sólo puede emerger cuando sea definido el papel de los organismos nacionales de cartografía", GeoFocus (Editorial), 3, pp. 1-4.

FREEMAN, T.W. (1961): A hundred years of geography. London, Duckworth.

FUENZALIDA DÍAZ, M. (2011): "Diseño de esquemas de localización optima para hospitales del servicio de salud Viña del Mar-Quillota (Chile) discriminando según status socio-económico", GeoFocus (Artículos), 11, pp. 409-430.

GARCÍA BACCA, J. D. (1986): Tres ejercicios literario-filosóficos de lógica y metafísica. Barcelona Anthropos.

GARDNER, H. E. (2006): Multiple intelligences: New horizons in theory and practice. Basic Books.

GÓMEZ MENDOZA, J., MUÑOZ JIMÉNEZ, J. y ORTEGA CANTERO, N. (1982): El pensamiento geográfico. Estudio interpretativo y antología de textos (de Humboldt a las tendencias radicales). Madrid, Alianza .

GÓMEZ MENDOZA, J. (2000): Rumbos de la Geografía del nuevo siglo. Una mirada desde Europa. Jornadas Interderpartamentales de Geografía de las Universidades Nacionales. Neuquén.

http://servidor-opsu.tach.ula.ve/profeso/sant_arm/l_c/pdf/rumbo_d.pdf

GOODCHILD, M. F:

- (2007): "Citizens as sensors: web 2.0 and the volunteering of geographic information", GeoFocus (Editorial), 7, pp. 8-10.

- (2010): "Twenty years of progress: GIScience in 2010", Journal of Spatial Information Science, 1, pp. 3 - 20.

GREGORY, D. (1978): Ideology, science and human geography. London, Hutchinson (Trad. esp.: Ideología, ciencia y geografía humana. Barcelona, Oikos Tau, 1984)

GRIMSHAW, D. (1994): Bringing geographical information systems into business. Harlow, Longman Scientific \& Technical.

GUELKE, L. (1978): "Geography and logical positivism", en D. T. Herbert y R. J. Johnston(ed): Geography and the urban environment. Progress in Research and Applications, v. I. Chichester, etc., John Wiley and Sons, pp. 35-62.

GUTIÉRREZ PUEBLA, J. (2005): "El tren de alta velocidad y sus efectos espaciales", Investigaciones Regionales, 5, pp. $199-221$.

HARVEY, D. (1969): Explanation in geography. Londres, Edward Arnold, (Trad. esp.: Teorías, leyes y modelos en Geografía. Madrid, Alianza, 1983)

HARVEY, F. (2008): A primer of GIS. Fundamental geographic and cartographic concepts. New York y Londres, The Guilford Press.

HARVEY, M. E. y HOLLY, B. P. (1981): Themes in geographical thought. London, Croom Helm.

HOLT-JENSEN, A. (1981): Geography. Its history and concepts. Londres, Harper and Row.

HUNTER, G.J. WACHOWICZ, M. y BREGT, A. K. (2003): "Understanding spatial data usability", Data Science Journal (Spatial Data Usability Special Section), 2, 26, pp. 79-89.

INNES, J.E. y SIMPSON, D. M. (1993): "Implementing GIS for planning. Lessons from the history of technological innovation", Journal of the American Planning Association, 59 (2), pp. 230 - 236.

JAMES, P. (1972): All possible worlds. A history of geographical ideas. New York, The Odissey Press. 
JOHNSTON, R. J:

- (1979): Geography and geographers. Anglo-american human geography since 1945. London, Edward Arnold.

- (1983): Philosophy and Human Geography. Londres, Edward Arnold

KWARTLER, M. y LONGO, G. (2008): Visioning and visualization: People, pixels and plans. Cambridge, Lincoln Institute of Land Policy.

KUHN, T. S. (1962): La estructura de las revoluciones cientificas. Fondo de Cultura Económica, edición 1971.

LAKATOS, I.:

- (1974): Historia de la ciencia y sus reconstrucciones racionales. Madrid, Tecnos.

- (1993): La metodología de los programas de investigación científica. Madrid, Alianza.

LAMELAS GRACIA, M.T. (2009): "Esquema metodológico para la toma de decisiones sobre el uso sostenible del suelo: Aplicación a la localización de suelo industrial", GeoFocus (Artículos), 9, pp. 28-66.

LÁZARO Y TORRES, M.L. DE y GONZÁLEZ GONZÁLEZ, M.J. (2005): La utilidad de los sistemas de información geográfica para la enseñanza de la Geografía, Didáctica Geográfica,7, pp. 105 - 122.

LLOYD, C. D. (2008): Spatial data analysis: an introduction for GIS users. Oxford, Oxford University Press.

LAUDAN, L::

- (1977): Progress and its problems. Berkeley, University of California Press (Trad. esp.: El progreso y sus problemas. Hacia una teoría del crecimiento científico. Madrid, Encuentro Ediciones, 1986).

- (1981): "A problem-solving approach to scientific progress", en Scientific revolutions, I. Hacking (Ed). Oxford, Oxford University Press, pp. 144-155.

LONGLEY, P., GOODCHILD, M., MAGUIRE, D. y RHIND, D. (2010): Geographic information systems and science. Wiley, $3^{\mathrm{a}}$ ed.

LUND, J.J. y SINTON, D. S. (2007): "Critical and creative visual thinking” en Sinton, D. S. y Lund, J.J.(eds.): Understanding place: GIS and mapping across the curriculum. ESRI Press, Redlands, California, pp. 1-16.

LUQUE REVUELTO, R. M. (2011): "El uso de la cartografía y la imagen digital como recurso didáctico en la enseñanza secundaria. Algunas precisiones en torno a Google Earth", Boletín de la Asociación de Geógrafos Españoles, 55, pp. 183-210. http://www.boletinage.com/55/09\%20AGE\%2055.pdf

MAANTAY, J. y ZIEGLER, J. (2006): GIS for the urban environment. ESRI Press.

MACEACHREN, A. y FRASER TAYLOR, D. (1994, Eds.): Visualization in modern cartography. Nueva York y Oxford, Pergamon.

MALDONADO IBÁÑEZ, A. y VÁZQUEZ HOEHNE, A. (2010): "Diseño de primitivas geométricas espacio-temporales para describir fenómenos dinámicos", GeoFocus (Artículos), 10, pp. 232-251.

MATEOS, P. (2013): "Geovisualización de la población: Nuevas tendencias en la web social", Investigaciones Geográficas, 60[en este número].

MÉNDEZ, R. (1989): "La filosofía de la tecnología del siglo XX", Anthropos, 94-95, pp. 27-34.

MEYNIER, A. (1969): Histoire de la pensée géographique en France. Paris, PUF.

MORENO JIMÉNEZ, A.:

- (1989): Proyecto docente. Madrid, Universidad Autónoma de Madrid, policopiado.

- (2007): “¿Está equitativamente repartida la contaminación sonora urbana? Una evaluación desde el principio de justicia ambiental en la ciudad de Madrid", Estudios Geográficos, 263, pp. 595-626. http://estudiosgeograficos.revistas.csic.es/index.php/estudiosgeograficos/article/view/70/67

- (2010): "GeoFocus: diez años en el camino hacia la sociedad de la geoinformación", GeoFocus (Editorial), 10, pp. 1-6.

MORENO JIMÉNEZ, A., BUZAI, G. D. y FUENZALIDA DÍAZ, M. (2012, Coor.): Sistemas de información geográfica. Aplicaciones en diagnósticos territoriales y decisiones geoambientales. Madrid, Ra-Ma. 
MORENO JIMÉNEZ, A. y CAÑADA TORRECILLA, R. (2007): "Justicia ambiental y contaminación atmosférica por dióxido de azufre en Madrid: análisis espacio-temporal y valoración con sistemas de información geográfica", Boletín de la Asociación de Geógrafos Españoles, 44, pp. 301-324.

http://age.ieg.csic.es/boletin/44/14-moreno.pdf

MOSTERIN, J. (1984): Conceptos y teoría en la ciencia. Madrid, Alianza.

MOULINES, C.U. (1982): Exploraciones metacientíficas. Estructura, desarrollo y contenido de la ciencia. Madrid, Alianza.

NAPOLEON, E. I. y BROOK, E. A. (2008): Thinking spatially using GIS Media Kit: Our world GIS education, Level 1. Redlands, ESRI Press.

NATIONAL RESEARCH COUNCIL:

- (2006a): Learning to think spatially. GIS as a support system in the K-12 Curriculum. Washington, DC: The National Academies Press. http://www.nap.edu/catalog.php?record id=11019

- (2006b): Learning to think spatially: GIS as a support system in the K-12 Curriculum (Free Executive Summary). http://www.nap.edu/catalog/11019.html

NEWTON-SMITH, W.H. (1981): The rationality of science. Boston, Routledge and Kegan Paul.

OBERLE, A. P., JOSEPH, S.A. y MAY, D. W. (2010): "Geospatial technologies as a vehicle for enhancing graduate education and promoting the value of geography", Journal of Geography in Higher Education, 34, 4, pp. $475-492$.

OJEDA ZÚJAR, J. (2010): Geovisualización: espacio, tiempo y territorio, Ciudad y Territorio Estudios Territoriales, 165-166, pp. $445-461$.

OJEDA ZÚJAR, J., ÁLVAREZ FRANCOSO, J. I., MARTÍN CAJARAVILLE, D. y FRAILE JURADO, P. (2009): "El uso de las TIG para el cálculo del indice de vulnerabilidad costera (CVI) ante una potencial subida del nivel del mar en la costa andaluza (España)", GeoFocus (Artículos), 9, pp. 83 - 100.

OJEDA ZÚJAR, J. y VILLAR LAMA, A. (2007): "Evolución del suelo urbano/alterado en el litoral de Andalucía", GeoFocus (Artículos), 7, pp. 73 - 99.

ORDÓÑEZ GALÁN, C., VARELA GONZÁLEZ, M. y REYES PANTOJA, A. (2011): "Desarrollo de un SIG para el análisis de patrones espaciales de incendios en viviendas”, GeoFocus (Artículos), 11, pp. 1-18.

PAEGELOW, M. y CAMACHO OLMEDO, M. T. (2008): Modelling environmental dynamics: Advances in geomatic solutions. Springer.

PARKER, R. N. y ASENCIO, E. K. (2008): GIS and spatial analysis for the social sciences. Coding, mapping and modeling. Londres, Routledge.

PETTIT, CH., CARTWRIGHT, W., BISHOP, I., LOWELL, K., PULLAR, D. y DUNCAN, D. (2008, Eds.): Landscape analysis and visualization. Spatial models for natural resource management and planning. Heidelberg, Springer Verlag.

PICKLES, J. (1995): "Representations in an electronic age. Geography, GIS, and democracy", en Pickles, J. (Ed.): Ground truth. The social implications of geographic information systems. New York, The Guilford Press, pp. 1-30.

PITT, J. C. (1988): Theories of explanation. Nueva York, Oxford University Press.

PLATA ROCHA, W., GÓMEZ DELGADO, M. y BOSQUE SENDRA, J. (2010): "Desarrollo de modelos de crecimiento urbano óptimo para la Comunidad de Madrid", GeoFocus (Artículos), 10, pp. 103 - 134.

POPPER, K.:

- (1968): The logic of scientific discovery. Londres, Hutchinson (Trad. esp.: La lógica de la investigación cientifica. Madrid, Tecnos, 1967).

- (1975): "The rationality of scientific revolutions", en R. Harré (Ed.): Problems of scientific revolutions. Oxford, Oxford University Press, pp. 72-101. Reimp. en Scientific Revolutions, I. Hacking, (Ed.). Oxford, Oxford University Press, pp. 80 - 107. 
PRAT, E., PESQUER, LL., OLIVET, M., ALOY, J., FUSTE, J. y PONS, X. (2009): "Metodología para el análisis de accesibilidad a los recursos sanitarios: el caso de Cataluña", GeoFocus (Artículos), 9, pp. 250 - 269.

QUAINI, M. (1981): La construcción de la geografía humana. Barcelona, Oikos Tau

QUIÑONERO RUBIO, J. M. y ALONSO SARRÍA, F. (2007): "Modelización de la dinámica hidrológica y erosiva en barrancos de la cuenca del río Quípar (sureste deEspaña) con GRASS", GeoFocus (Artículos), 7, pp. $188-215$.

RAMBALDI, G., KIEM, P., MCCALL, M. y WEINER, D. (2006): "Participatory spatial information management and communication in developing countries", Electronic Journal of Information Systems in Developing Countries, 25, pp. 1-9. http://www.ejisdc.org/ojs2/index.php/ejisdc/article/view/238/159

RUIZ PÉREZ, M. (2012): "Vulnerabilidad territorial frente a desastres naturales: el caso de la isla de Mallorca (Baleares, España)", GeoFocus (Artículos), 12, p 16-52.

ROMERO MÉNDEZ, A. y MONTES GALBÁN, E. (2009): "Evaluación espacio - temporal de la sedimentación en el embalse Burro Negro, estado Zulia / Venezuela mediante el uso combinado de SIG - Ecosonda - DGPS", GeoFocus (Artículos), 9, pp. 209-231.

SCHUURMAN, N. (2004): GIS: A short introduction. John Wiley \& Sons.

SIEBER, R.E. (2006): "Public participation geographic information systems: A literature review and framework", Annals of the Association of American Geographers, 96, pp. 491 - 507

SINTON, D.S. y LUND, J.J. (2007): Understanding place: GIS and mapping across the curriculum. ESRI Press, Redlands, California.

SMITH, I. (1964): Spatial ability: Its educational and spatial significance. San Diego (Calif.), R. R. Knapp.

STEINBERG, S.J. y STEINBERG, S. L. (2006): Geographical information systems for the social sciences. Investigating space and place. Thousands Oaks, etc. Sage.

STILLWELL, J, GEERTMAN, S. y OPENSHAW, S. (1999, Ed.): Geographical information and planning. Berlín, Springer.

STODDART, D. R. (1981): "The paradigm concept and the history of geography", en D. R. Stoddart (Ed.): Geography, ideology and social concern. Oxford, Basil Blackwell, pp.70-80.

SUI, D.Z. y MORRILL, R. (2004): "Computers and Geography: From Automated Geography to Digital Earth”, en Brunn, S. D., Cutter, S. I. y Harrington, J. W. Jr. (Eds.). Geography and Technology. Amsterdam: Kluwer Academic Publishers, pp. 81-108.

TOMLINSON, R. (2007): Pensando en SIG. Redlands, ESRI Press, $3^{\mathrm{a}}$ ed.

TORRENS, P. M. (2010): "Geography and computational social science", GeoJournal, 75 (2), pp. 133-148.

TOUDERT, D. y BRINGAS R., N. L. (2010): "Planeación participativa en el engranaje del ordenamiento ecológico: la apropiación social de las tecnologías de la información geográfica”, Geografía y Sistemas de Información Geográfica (GEOSIG), 2, Sección Artículos, pp. 186-199.

http://www.gesig-proeg.com.ar/documentos/revista-geosig/2010/TOUDERT-BRINGAS.pdf

THUILLIER, P. (1975): La manipulación de la ciencia. Caracas, Fundamentos.

VARNI, M., ENTRAIGAS, I. y GANDINI, M.(2006): "Propuesta de dos métodos para el mapeo de áreas anegadas utilizando condiciones hidrológicas cuantificables", GeoFocus (Artículos), 6, pp.33 - 46.

VEREGIN, H. (1995): "Computer innovation and adoption in Geography", en Pickles, J. (Ed.): Ground truth. The social implications of geographic information systems. New York, The Guilford Press, pp. 88-112.

WINNER, L. (1977): Autonomous technology: Technics-out-of-control as a theme in political thought. Cambridge, MA, MIT Press.

WACHOWICZ, M. RIEDEMANN, C., VULlinGS, W., SUÁREZ, J. y CROMVOETS, J. (2002): "Workshop report on spatial data usability”. Proceedings AGILE 2002 Conference on GI Science, April. Mallorca, Spain. 
WACHOWICZ, M., VUlliNGS, W., BULENS, J. DE GROOT, H. y VAN DEN BROEK, M. (2005): "Uncovering the main elements of geo-web usability". Proceedings 8th AGILE Conference on GIScience, June. Lisbon, Portugal.

WACHOWICZ, M., CUI, L., VULLINGS, W. y BULENS, J. (2007): "The effects of web mapping applications on user satisfaction: an empirical study", en Peterson, M. (Ed.): International perspectives on maps and the Internet, Springer-Verlag.

WARTOFSKY, M.W. (1968): Conceptual foundations of scientific thought: An introduction to the philosophy of science. New York, Mac Millan. (Trad. esp.: Introducción a la filosofía de la ciencia. Barcelona, Alianza Editorial, 1976, 2 ed.)

WILBANKS, T. (2004): "Geography and technology" en Brunn, S. D., Cutter, S. I. y HARRINGTON, J. W. JR. (Eds.). Geography and Technology. Amsterdam, Kluwer Academic Publishers, pp. 3 - 16.

WILSON, A. G. (1980): "Theory in human geography", en E. H. Brown (ed.): Geography. Yesterday and tomorrow. Oxford University Press (Trad. esp.:"La teoría en la geografía humana. Un ensayo de reseña", en E. H. Brown (ed.): Geografía, pasado y futuro. México, FCE, 1985, pp. 287 - 305).

WINCH, P. (1958): The idea of a social science and its relation to philosophy. Londres, Routledge and Kegan Paul.

WRIGHT, D., GOODCHILD, M. y PROCTOR, J. (1997): "GIS: tool or science", Annals of the Association of American Geographers, 87, 2, pp. 346-362. 